\title{
Climatological Changes in the Extratropical Transition of Tropical Cyclones in High-Resolution Global Simulations $\mathscr{d}$
}

\author{
ALlison C. Michaelis \\ Center for Western Weather and Water Extremes, Scripps Institution of Oceanography, La Jolla, California \\ GARY M. LACKMANN \\ Department of Marine, Earth, and Atmospheric Sciences, North Carolina State University, Raleigh, North Carolina
}

(Manuscript received 2 April 2019, in final form 11 September 2019)

\begin{abstract}
Tropical cyclones (TCs) undergoing extratropical transition (ET) can develop into intense cyclonic systems accompanied by high-impact weather in areas far removed from the original TC. This study presents an analysis of multiseasonal global simulations representative of present-day and projected future climates using the Model for Prediction Across Scales-Atmosphere (MPAS-A), with high resolution (15-km grid) throughout the Northern Hemisphere. TCs are tracked as minima in sea level pressure (SLP) accompanied by a warm core, and TC tracks are extended into the extratropical phase based on local minima in SLP and use of a cyclone phase space method. The present-day simulations adequately represent observed ET characteristics such as frequency, location, and seasonal cycles throughout the Northern Hemisphere. The most significant changes in future ET events occur in the North Atlantic (NATL) basin. Here, a more favorable background environment, a shift toward stronger TC warm cores in the lower troposphere, and a significant poleward shift in TC location lead to a $\sim 40 \%$ increase in the number of NATL ET events and a $\sim 6 \%$ increase in the fraction of TCs undergoing ET. This equates to approximately 1-2 additional ET events per year in this region. In the future simulations, ET in the NATL occurs markedly farther north by $\sim 4^{\circ}-5^{\circ} \mathrm{N}$, and the resultant extratropical cyclones are stronger by $\sim 6 \mathrm{hPa}$. These changes hold potentially important implications for areas directly affected by ET events, such as eastern North America, as well as for regions indirectly impacted by downstream effects, including western Europe.
\end{abstract}

\section{Introduction}

The extratropical transition (ET) of tropical cyclones (TCs) occurs when a tropical cyclone translates into the midlatitudes, interacts with midlatitude features such as an upper-level trough or extratropical cyclone (ETC), and transforms from a symmetric, warm-core tropical system to an asymmetric, cold-core extratropical system, effectively replacing the original TC characteristics with a baroclinic structure (e.g., Jones et al. 2003; Arnott et al. 2004; Kofron et al. 2010b; Kitabatake 2011; Wood and Ritchie 2014; Evans et al. 2017). During the

\footnotetext{
Supplemental information related to this paper is available at the Journals Online website: https://doi.org/10.1175/JCLI-D-190259.s1.

Corresponding author: Allison C. Michaelis, allison.c.michaelis@ gmail.com
}

transition process, a TC can experience environmental changes such as increased baroclinicity, cooler sea surface temperatures (SSTs), stronger SST gradients, and/or interactions with existing midlatitude troughs or cyclones (e.g., Jones et al. 2003; Kofron et al. 2010a). These changes can induce structural modifications to the TC, including loss of a symmetric inner core, expanded asymmetric distributions of wind and precipitation, and increased translation speeds, which allow the system to impact a greater area as it transitions (Klein et al. 2000; Jones et al. 2003; Wood and Ritchie 2014; Evans et al. 2017).

TCs undergoing ET can develop into intense cyclonic systems that bring TC-like conditions (e.g., intense rainfall, strong winds, large waves) to areas far removed from the original TC (Malmquist 1999; Jones et al. 2003; Kitabatake 2011). Additional hazards associated with ET events include inland flooding, wind-induced wildfires, and sinking of ships (Arnott et al. 2004, and references 
therein). Transoceanic shipping routes in late summer and early autumn often shift poleward to benefit from calmer conditions and avoidance of TCs; however, TCs that recurve poleward into these regions and undergo ET can pose serious threats (Harr and Elsberry 2000). Major cities along the U.S. East Coast such as Washington, D.C., New York, New York, and Boston, Massachusetts, experience an ET event every two to four years; western Europe is affected by an ET event about every two years (Hart and Evans 2001). Recent examples of such events that affected the U.S. include Irene (2011) and Sandy (2012); the latter resulted in $2 \mathrm{~m}$ $(\sim 6.5 \mathrm{ft})$ of storm surge and over $900 \mathrm{~mm}(\sim 3 \mathrm{ft})$ of snow across parts of the northeast United States (Evans et al. 2017, and references therein). Additionally, these events can adversely affect predictive skill on hemispheric scales, owing to downstream dispersion of Rossby wave energy; the outflow from recurving or transitioning TCs can modify midlatitude flow and lead to high-impact weather events, such as cold-air outbreaks or heavy precipitation, downstream of the original TC (e.g., Harr and Dea 2009; Archambault et al. 2013, 2015; Keller et al. 2019).

While previous research has looked extensively at the ET process, and numerous studies have investigated climate change effects on tropical cyclones, relatively few studies have examined how ET events may be affected by climate change (Evans et al. 2017; Jung and Lackmann 2019). This complicated problem involves changes in TCs (e.g., frequency, intensity, location) as well as changes in the midlatitude environment. Early investigations into this problem by Walsh and Katzfey (2000) and Semmler et al. (2008) were limited by coarse model resolution. More recently, several studies have hypothesized that warmer SSTs, reduced vertical wind shear in the North Atlantic tropical and subtropical regions, and a projected eastward extension of the North Atlantic hurricane development region could allow TCs to survive in the midlatitudes longer, thus increasing the frequency of ET events (Haarsma et al. 2013; Baatsen et al. 2015; Liu et al. 2017). Furthermore, TCs that undergo ET could have a higher chance of regaining hurricane force winds in a future climate due to projected increases in moisture and subsequent latent heat release (Haarsma et al. 2013). Conversely, a case study of Typhoon Songda (2004) conducted by Ito et al. (2016) showed that weakening baroclinicity in the western North Pacific created a less favorable environment and a weaker future ET event. ET events have been shown to produce devastating storm surges along midlatitude coastlines, but research is lacking in how climate change will affect these hybrid storms and their subsequent impacts along the U.S. East Coast (Colle et al. 2015; Booth et al. 2016). To fully address potential changes to the future impacts of these storms, we need to understand how the location, frequency, and intensity of ET events may change under future climate conditions, thus defining the goal of this research.

As a complement to pseudo-global warming (PGW) case studies such as Lackmann (2015) and Jung and Lackmann (2019), here we analyze a set of novel highresolution (15-km grid) multiseasonal simulations conducted in present and projected future environments using the Model for Prediction Across Scales-Atmosphere [MPAS-A; see Michaelis et al. (2019) for a complete technical description of the simulation design]. In addition to high resolution, these simulations include a unique approach to lower boundary forcing that retains detailed, realistic SST features for both present-day and future simulations. Future simulations utilize lowerboundary change fields derived from an ensemble of Intergovernmental Panel on Climate Change (IPCC) general circulation models (GCMs) under the representative concentration pathway (RCP) 8.5 emissions scenario. The remainder of the paper is organized as follows: section 2 describes the model simulations and cyclone tracking techniques; section 3 evaluates the present-day climate simulations in comparison to observed ET climatology; section 4 presents projected future changes in the ET climatology; and section 5 includes a summary of results, concluding remarks, and ideas for future work.

\section{Data and methods}

\section{a. Model simulations}

We analyze a set of time-slice simulations conducted using the atmospheric component of MPAS, version 5.1 (Skamarock et al. 2012); a complete technical description of these simulations is presented in Michaelis et al. (2019). Our global model domain employs a variableresolution mesh with $15-\mathrm{km}$ horizontal grid spacing throughout the entire Northern Hemisphere, expanding to $60 \mathrm{~km}$ in the Southern Hemisphere (Fig. 1). A grid spacing of $15 \mathrm{~km}$ ensures a more accurate representation of storm-scale processes, namely those affected by latent heat release, compared to traditional GCMs with grid spacings on the order of $\sim 100 \mathrm{~km}$ (Willison et al. 2013). Although we would optimally perform simulations with a convection-allowing grid length (e.g., Gentry and Lackmann 2010), 15-km grid spacing is sufficient for producing realistic tropical cyclones (Davis et al. 2016; Davis 2018). In fact, our 15-km MPAS-A simulations are capable of representing intense tropical cyclones (Fig. 2), also shown by Michaelis et al. (2019, their Fig. 7). 


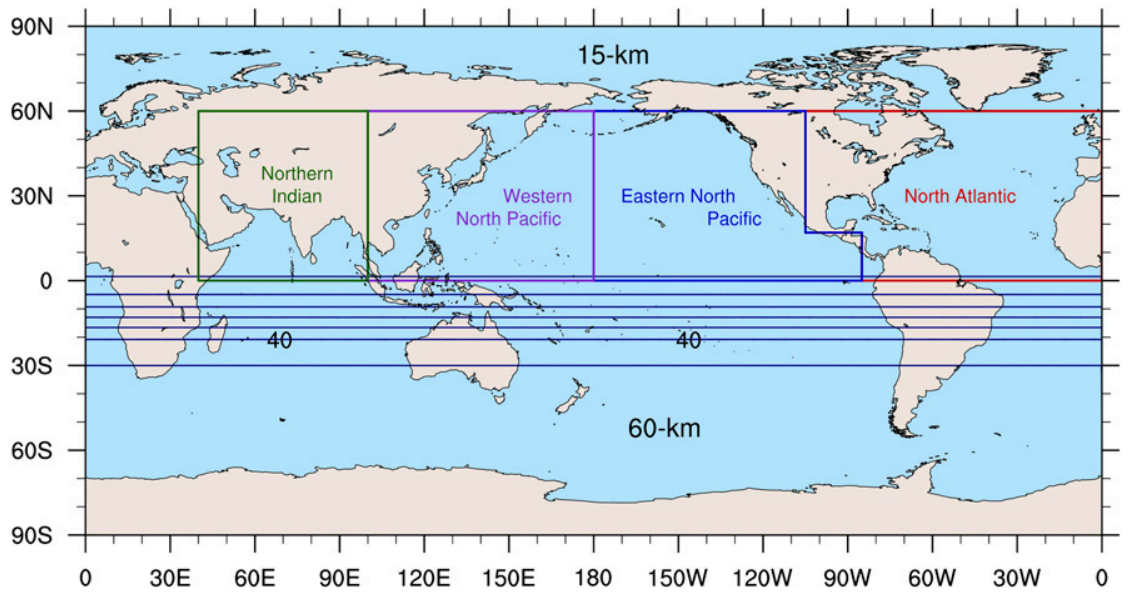

FIG. 1. Variable-resolution mesh used in MPAS-A simulations and geographical regions of the tropical cyclone basins defined in this study.

We simulate 10 years to sample varying phases of El Niño-Southern Oscillation (ENSO; Table 1) using analyzed SST patterns from the Operational Sea Surface Temperature and Sea ice Analysis (OSTIA; Donlon et al. 2012). Additionally, we incorporate daily sea ice fields created from climatological monthly-mean values taken from a GCM ensemble mean. Our simulations span 14.5 months from 1 March of the first year through 14 May of the second year; the first month is discarded as spin up, and output is recorded at 6-h intervals. Physics parameterizations for these simulations include Tiedtke subgrid-scale convection, WRF single-moment 6-class
(WSM6) microphysics, Yonsei University (YSU) planetary boundary layer, Community Atmosphere Model (CAM) shortwave and longwave radiation, and the Noah land surface model for surface processes.

The treatment of lower boundary conditions in our future simulations is in some sense similar to PGW methods (e.g., Schär et al. 1996; Frei et al. 1998; Kimura and Kitoh 2007; Hara et al. 2008; Rasmussen et al. 2011; Mallard et al. 2013a; Lackmann 2013, 2015; Trapp and Hoogewind 2016; Gutman et al. 2018), but without the constraint of lateral boundary conditions. For the future simulations, we apply temperature changes derived
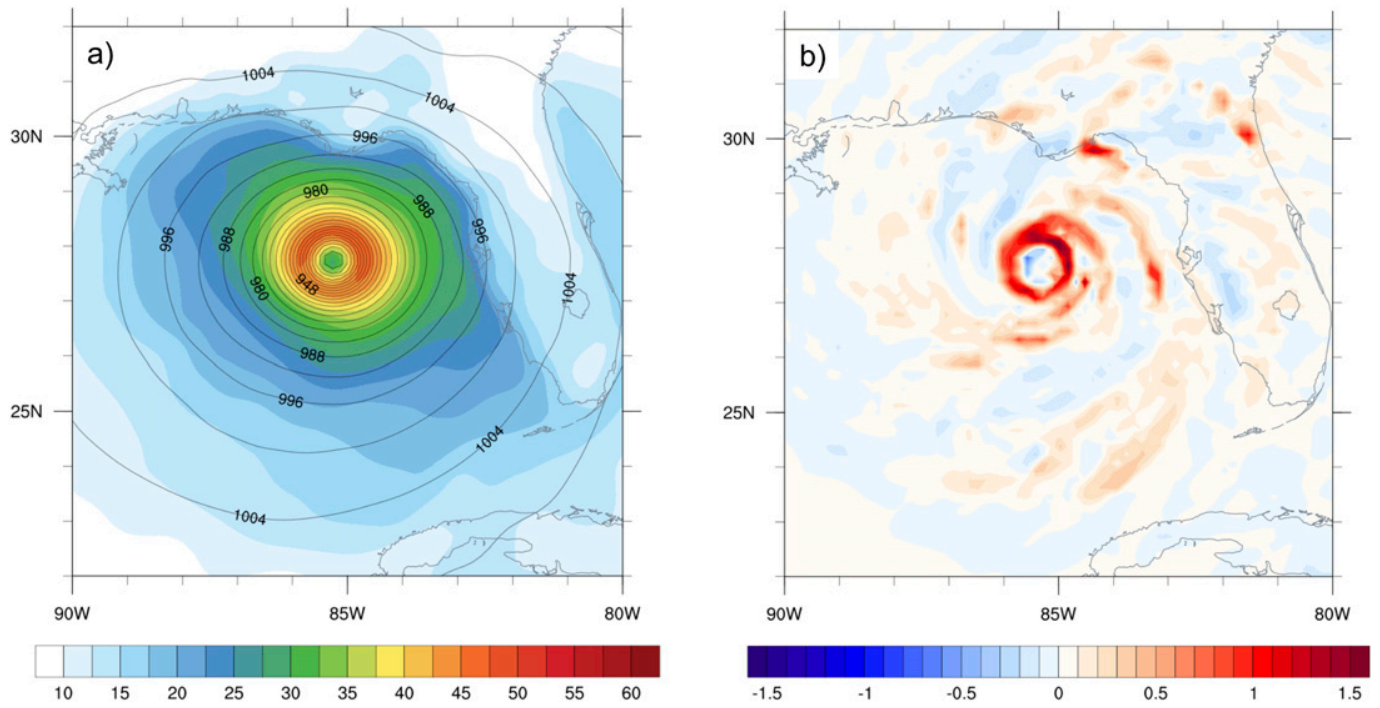

FIG. 2. (a) Sea level pressure (hPa; contours) and 10-m wind speed ( $\mathrm{m} \mathrm{s}^{-1}$; shaded) and (b) 700-hPa vertical velocity ( $\mathrm{m} \mathrm{s}^{-1}$; shaded) for an example North Atlantic TC from the present-day MPAS-A simulations. SLP in (a) is contoured every $4 \mathrm{hPa}$, reaching a minimum SLP of $\sim 915 \mathrm{hPa}$. Velocities in (a) and (b) are shaded every 2.5 and $0.1 \mathrm{~m} \mathrm{~s}^{-1}$, respectively. 
TABLE 1. Simulation years and corresponding ENSO phase during the TC season (June-November).

\begin{tabular}{ll}
\hline \hline Year & ENSO phase \\
\hline 2010 & Strong La Niña \\
1988 & Strong La Niña \\
2011 & Weak La Niña \\
2013 & Neutral \\
2001 & Neutral \\
2005 & Neutral \\
1992 & Neutral \\
1994 & Weak El Niño \\
2015 & Strong El Niño \\
1997 & Strong El Niño \\
\hline
\end{tabular}

from an ensemble GCMs from phase 5 of the Coupled Model Intercomparison Project (CMIP5) following the IPCC Fifth Assessment Report (AR5) RCP8.5 emissions scenario to the high-resolution analyses used for our present-day simulations, including SSTs, deep soil temperatures, and, just for a single-year spinup simulation, to atmospheric temperatures at all levels. Additionally, we incorporate daily sea ice derived from this GCM ensemble under future climate conditions and set carbon dioxide $\left(\mathrm{CO}_{2}\right)$ concentrations in the future climate simulations to $936 \mathrm{ppm}$, consistent with the RCP8.5 emissions scenario projections for the year 2100 (Meinshausen et al. 2011). With this configuration and experimental design, MPAS-A is able to produce and maintain temperature change patterns that are remarkably similar to those produced by IPCC-class GCMs (Michaelis et al. 2019).

Within a few weeks, the simulated synoptic pattern is fully decorrelated with analyzed weather, and the model generates a quasi-independent climate state. By using analyzed, high-resolution SST patterns in both presentday and future simulations (Figs. S1 and S2 in the online supplemental material), our simulations provide realistic midlatitude storm tracks and jet streams (Michaelis et al. 2019). We use the same pseudo-climatological sea ice field in each present-day simulation (Fig. S3) and the same modified sea ice field in each future simulation (Fig. S4). Thus, while we omit the effects of interannual sea ice variability, our simulations can be used to study changes attributable to Arctic sea ice loss. In our future simulations, the Arctic is mostly ice free from late August to early October (Fig. S4). Additional information regarding the limitations of our simulation technique and evaluation of the present-day model climate is provided by Michaelis et al. (2019).

\section{b. Tropical cyclone tracking}

We utilize the TempestExtremes feature-based tracking algorithm (Ullrich and Zarzycki 2017; Zarzycki and
Ullrich 2017) to objectively identify simulated tropical cyclones in each Northern Hemispheric basin (Fig. 1). Storm centers are first detected as minima in SLP, and are retained as candidate TC centers if certain criteria, such as a 2 -hPa closed SLP contour within $2^{\circ}$ of the storm center and a 300-500-hPa geopotential thickness maximum within $6^{\circ}$ of the storm center, are met. This former criterion places a strength requirement on the storm, while the latter ensures the presence of a warm core. Additional specifications for our TC tracks include a travel distance of no more than $6^{\circ}$ within a 6-h period, a total lifetime of at least two days, and at least two days with maximum $10-\mathrm{m}$ wind speeds $\geq 14 \mathrm{~m} \mathrm{~s}^{-1}$ ( $\left.\sim 31 \mathrm{mph}\right)$. While we allow TempestExtremes to identify candidate centers as far north as $60^{\circ} \mathrm{N}$ to prevent the premature termination of trajectories, we postprocess the tracks to eliminate TCs with a genesis latitude north of $45^{\circ} \mathrm{N}$. To prevent broken tracks from being double-counted, trajectories are merged together if they end and begin within $12 \mathrm{~h}$ of each other. Last, TCs are separated into basins (Fig. 1) based on the location of TC genesis. A comprehensive list of tunable parameters for TempestExtremes, as well as our choices for each, is included in Table 2.3 of Michaelis (2019). Results of the TempestExtremes algorithm are most sensitive to the strength of the SLP minimum and warm core (Zarzycki and Ullrich 2017). We performed sensitivity tests adjusting these factors; results did not vary significantly from those with our chosen configuration (not shown).

In general, the simulated spatial distribution of TC activity matches observations reasonably well, with the exception of the eastern North Atlantic (Figs. 3a,b). There, a positive bias in vertical wind shear, and a westward shift in the simulated African easterly jet, apparently inhibit TC development [not shown; see Done et al. (2011) and Michaelis et al. (2019) for further discussion]. Analysis of TC intensity in the present-day simulations demonstrates that the model is capable of representing intense tropical cyclones (Fig 2; Michaelis et al. 2019, their Fig. 7), especially when measured using minimum sea level pressure. Although our simulations parameterize convection, simulated TCs exhibit central pressures comparable to the most intense observed systems, as well as realistic TC features such as a welldefined eye (Fig. 2).

\section{c. Detection of extratropical transition events}

We use the ExTraTrack extratropical transition tracker (Zarzycki et al. 2017) to detect simulated ET events in the present-day and future simulations. ExTraTrack is an objective algorithm that continues TC trajectories from TempestExtremes based on local minima in SLP. Candidate centers are first identified as local minima in 


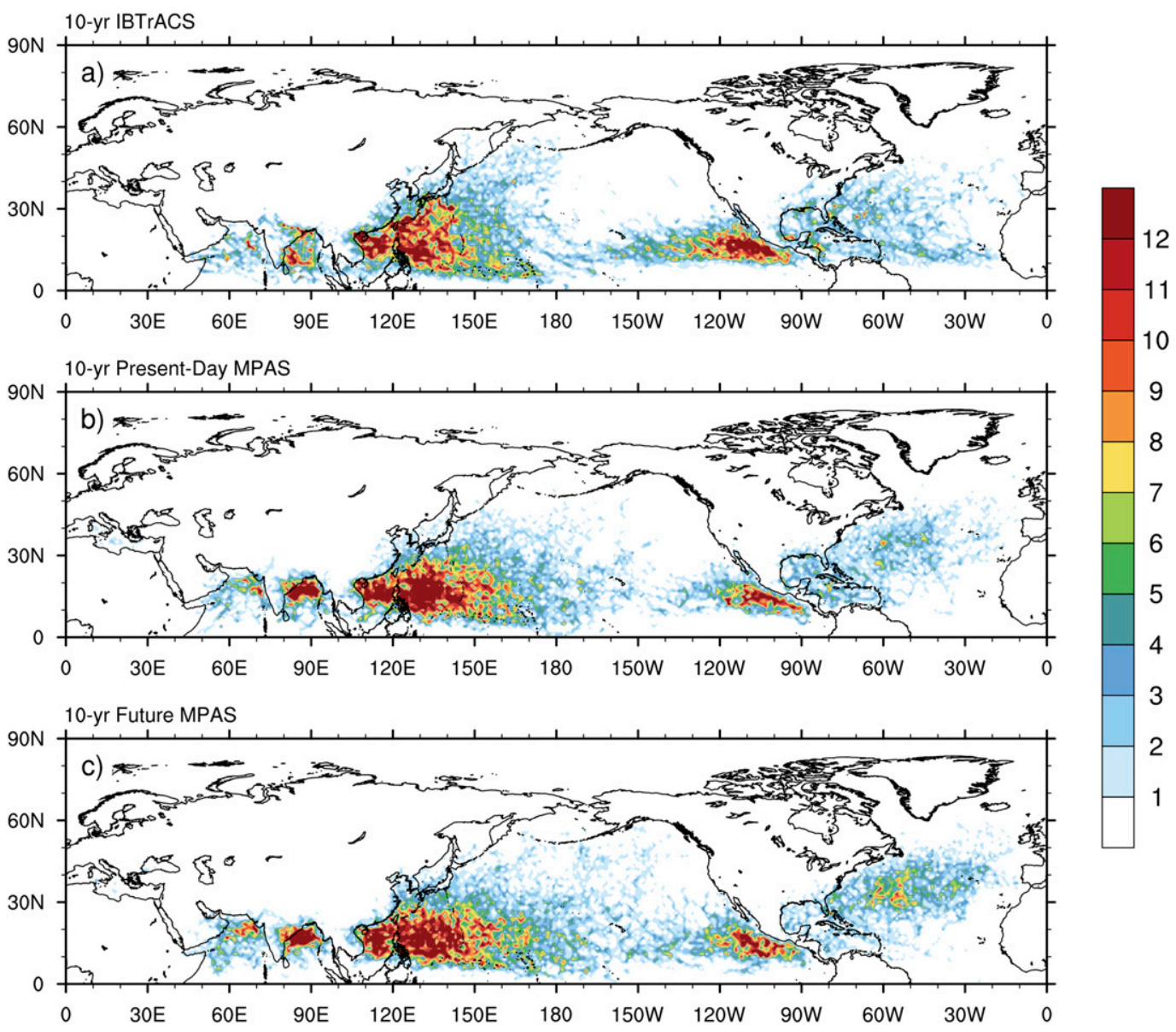

FIG. 3. Track density (number of cyclone tracks per $1^{\circ} \times 1^{\circ}$ area) over the ten simulated years for (a) IBTrACS, (b) present-day MPAS-A simulations, and (c) future MPAS-A simulations. Contours are shaded every 1 count in all panels.

SLP compared to their eight surrounding neighbors. Due to the high resolution of our model output, we implement a secondary local minimum check using neighboring grid points that are three grid points away from the candidate center. Additionally, candidate centers are discarded if the minimum SLP is greater than $1020 \mathrm{hPa}$, or if the center is over topography greater than $350 \mathrm{~m}$ in altitude. If multiple candidate centers are detected, the center with the lowest minimum SLP is retained. The storm propagation speed is limited to $40 \mathrm{~m} \mathrm{~s}^{-1}$, which constrains the search radius for candidate centers, and changes in storm direction are restricted based on storm speed to prevent sharp changes in storm direction from occurring. For example, storms moving between 10 and $15 \mathrm{~m} \mathrm{~s}^{-1}$ are allowed a change in storm direction up to $135^{\circ}$ while faster moving storms (i.e., those moving at least $30 \mathrm{~m} \mathrm{~s}^{-1}$ ) are only allowed a $45^{\circ}$ change in track direction. In our configuration, ExTraTrack does not track TCs from TempestExtremes if they occur in the northern Indian (NI) basin (Fig. 1) or dissipate south of $20^{\circ} \mathrm{N}$.

The cyclone phase space (CPS; Hart 2003) method is used to objectively detect and quantify simulated ET events through examination of storm structure. The level of symmetry of a cyclone is determined by its $900-600-\mathrm{hPa}$ thickness symmetry $(B)$, calculated as

$$
B=\overline{Z_{600 \mathrm{hPa}}-\left.Z_{900 \mathrm{hPa}}\right|_{R}}-\overline{Z_{600 \mathrm{hPa}}-\left.Z_{900 \mathrm{hPa}}\right|_{L}},
$$

where $Z$ is the geopotential height at $600-$ and $900-\mathrm{hPa}$ levels, $R$ and $L$ indicate the right and left hemispheres of the storm relative to storm motion, respectively, and the overbar denotes an average value within a $500-\mathrm{km}$ radius of the cyclone center. Generally, large values of $B$ indicate an asymmetric nature, and vice versa. The temperature and strength of the cyclone core is determined by the lower-tropospheric (900-600-hPa) thermal wind $(-\mathrm{VLT})$, calculated as 

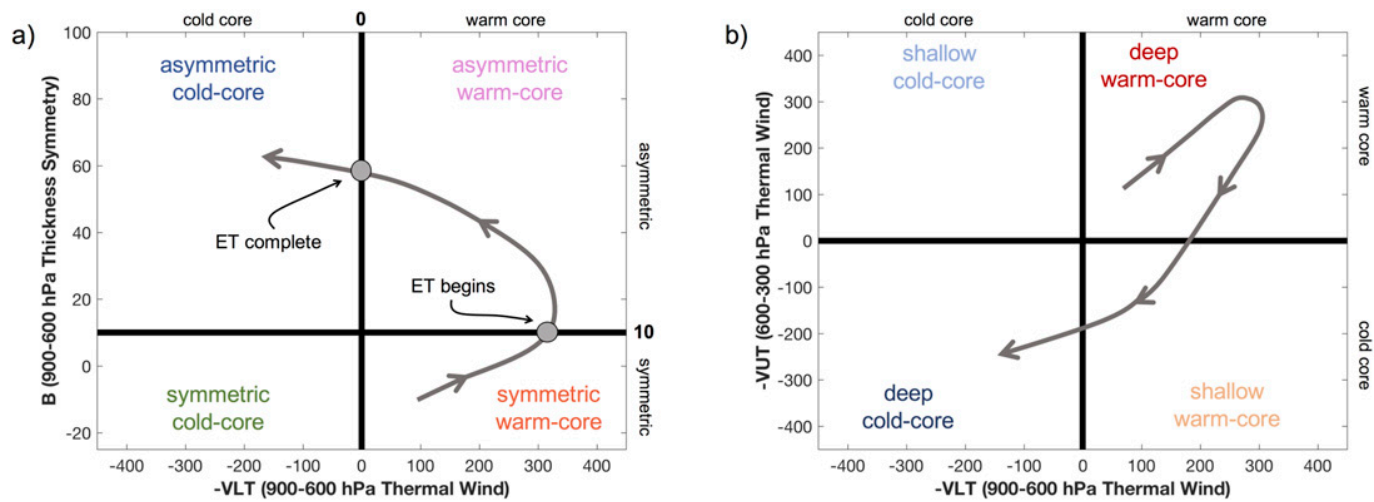

FIG. 4. Adapted from Zarzycki et al. (2017): overview of the cyclone phase space (CPS) diagrams for (a) - VLT vs $B$ and (b) - VLT vs - VUT.

$$
-\mathrm{VLT}=\left.\frac{\partial \Delta Z}{\partial \ln p}\right|_{900 \mathrm{hPa}} ^{600 \mathrm{hPa}},
$$

and the upper-tropospheric (600-300-hPa) thermal wind (-VUT), calculated as

$$
-\mathrm{VUT}=\left.\frac{\partial \Delta Z}{\partial \ln p}\right|_{600 \mathrm{hPa}} ^{300 \mathrm{hPa}},
$$

where the vertical profiles of the height perturbation $\left(\Delta Z=Z_{\max }-Z_{\min }\right)$ are computed using pressure levels from 300 to $900 \mathrm{hPa}$ at $50-\mathrm{hPa}$ intervals. A positive thermal wind signifies a warm-core cyclone. Likewise, a negative thermal wind indicates a cold-core structure.

Similar to previous studies, our simulated TCs have $B<10$ and - VLT $>0$, indicating a symmetric, warm-core structure, and simulated ETCs have $B>10$ and $-\mathrm{VLT}<0$, signifying an asymmetric, cold-core structure (Fig. 4; Evans and Hart 2003; Hart et al. 2006; Kitabatake 2011). Cluster analysis of 19 ET events from 1998 to 2002 by Arnott et al. (2004) provides additional confidence in using these thresholds. Zarzycki et al. (2017) increased the $B$ threshold from 10 to 15 to account for high-resolution data; however, preliminary analysis of ET events in our model output suggests that maintaining the $B$ threshold at 10 is appropriate. The onset of transition occurs when either $B$ first becomes greater than 10 or -VLT first becomes negative; ET completion is declared when the alternate criterion is met (i.e., if ET onset is declared when $B$ first becomes greater than 10, then ET completion occurs when -VLT first becomes negative, and vice versa). Satisfying both criteria indicates the cyclone has fully transitioned from a TC to an ETC (Evans and Hart 2003; Hart 2003; Haarsma et al. 2013; Wood and Ritchie 2014; Zarzycki et al. 2017).

ExTraTrack computes the aforementioned CPS parameters at each output time along the cyclone trajectory (i.e., every $6 \mathrm{~h}$ ) to determine the storm structure throughout its life cycle. A 24-h running mean is used to smooth the CPS values prior to analysis. A cyclone must maintain tropical characteristics (i.e., $B<10$ and - VLT $>0$ ) for at least the first 1.5 days of its trajectory. If this is not the case, the cyclone is categorized as a subtropical cyclone. To be categorized as an ET event, cyclones must fulfill the $B$ and -VLT criteria for 12 consecutive hours; storms that satisfy only one criterion are categorized as partial ET events. Partial ET events are typically events that dissipate prior to ET completion, or transition back to a TC before completing ET. Last, cyclones detected by ExTraTrack that do not meet either ET criteria, or dissipate south of $20^{\circ} \mathrm{N}$, are categorized as TCs. The former generally being weaker cyclones with shallow warm cores. Our analysis in the following sections will focus only on cyclones in the ET category.

\section{Model present-day extratropical transition climatology}

Due to the low frequency of ET in the eastern North Pacific (ENP; Wood and Ritchie 2014; Bieli et al. 2019), we only evaluate the present-day MPAS-A ET climatology for the North Atlantic (NATL) and western North Pacific (WNP) basins. Here, we compare simulated ET to the International Best Track Archive for Climate Stewardship (IBTrACS; Knapp et al. 2010) over the 10 simulation years. As previously mentioned, an MPAS-A cyclone must maintain tropical characteristics for at least the first 1.5 days of its lifetime, and satisfy both CPS criteria $(B>10$ and - VLT $<0)$ for at least $12 \mathrm{~h}$ to be considered an ET event. Meteorological agencies, such as the National Hurricane Center (NHC) and the Japan Meteorological Agency (JMA), typically declare the time of ET subjectively using satellite imagery and surface observations to determine when the system no longer exhibits tropical characteristics 
TABLE 2. Number of TCs, ET events, and percent of TCs that undergo transition in the North Atlantic and western North Pacific basins over the 10 simulation years for IBTrACS and for present-day MPAS-A simulations. The percent transition range of internal variability for IBTrACS is determined by calculating the percent of transitioning TCs for 10010 -yr samples.

\begin{tabular}{lccccc}
\hline \hline Basin & Data source & No. of TCs & No. of ET events & \% transition & $\begin{array}{c}\text { \% transition: Range of } \\
\text { observed variability }\end{array}$ \\
\hline NATL & IBTrACS & 141 & 49 & 35 & $20-47$ \\
WNP & MPAS-A & 189 & 60 & 32 & 37 \\
& IBTrACS & 300 & 112 & 32 & $30-44$ \\
\hline
\end{tabular}

(Hart and Evans 2001; Kitabatake 2011; Zarzycki et al. 2017). In the IBTrACS, this identification is denoted with an "ET" tag in the recorded track, thus defining a storm as an ETC. Therefore, it follows that we use this ET tag as a declaration of ET completion for observed TCs. Here, we include all IBTrACS cyclones that were categorized as an ETC at any point during their lifetime, excluding first 1.5 days to be consistent with our MPAS-A definition (i.e., a TC is not included for analysis if it begins as an ETC and undergoes tropical transition). Additionally, any unnamed storms are removed from IBTrACS prior to analysis to remain consistent with previous work (e.g., Zarzycki et al. 2017).

\section{a. Frequency and seasonal cycle}

In both basins, MPAS-A generates more TC activity compared to IBTrACS (Table 2). TC activity in the NATL is within the range of observed variability, but MPAS-A does overestimate TC frequency in the WNP (Michaelis et al. 2019, their Fig. 8 and section 4). For the NATL, the IBTrACS 10-yr ET percentage is lower than the range of previously published estimates for this basin ( $~ 35 \%$ compared to $42 \%-55 \%$; Hart and Evans 2001; Jones et al. 2003; Zarzycki et al. 2017; Bieli et al. 2019). Calculation of percent transition for IBTrACS from 1980-2002, however, resulted in $46 \%$ of TCs undergoing ET, consistent with Zarzycki et al. (2017). Additionally, the IBTrACS 10-yr ET percentage falls within the bounds of observed variability (Table 2). For the WNP, the IBTrACS 10-yr percent transition is consistent with the range of published estimates $(\sim 37 \%$ compared to 28\%-56\%; Klein et al. 2000; Kitabatake 2011; Bieli et al. 2019). The ET percentages for the present-day MPAS-A simulations are slightly lower than IBTrACS for both the NATL and WNP basins, but are still well within the observed ranges of variability (Table 2).

In the NATL, the number of ET events in the presentday MPAS-A simulations increases during the summer months, reaches a maximum in September, and decreases thereafter (Fig. 5a). This seasonal cycle in the latter portion of the TC season (i.e., after September) is consistent with IBTrACS (Fig. 5c) and previous studies (Hart and Evans 2001; Zarzycki et al. 2017;
Bieli et al. 2019). Our simulations produce too many ET events in the shoulder months surrounding the TC season, primarily due to the overproduction of TCs. The seasonality of the fraction of TCs undergoing ET between IBTrACS and MPAS-A exhibits clear differences (Figs. 5a,c). For example, a secondary maximum in IBTrACS ET percentage occurs in June when the fraction of TCs that undergo ET is at an absolute minimum in the MPAS-A simulations. The seasonality in percent transition produced by the MPAS-A simulations somewhat resembles the ERA-I seasonal cycle presented by Zarzycki et al. (2017, their Fig. 7) with maxima in July and September and minima in June and October. Studholme et al. (2015) also showed a seasonal ET cycle for the NATL with relatively high ET percentages from July through October (their Fig. 13), not unlike what is shown here for our MPAS-A simulations (Fig. 5a). According to Hart and Evans (2001), the highest percentage of ET events occurs in the late fall when baroclinically favorable and tropically favorable regions are in closest proximity. Our MPAS-A simulations instead show ET percentage maximized in late summer/early fall. There is clearly substantial variation in the literature regarding the seasonality of percent transition for the NATL (Hart and Evans 2001; Studholme et al. 2015; Zarzycki et al. 2017; Bieli et al. 2019), likely due to the large uncertainty in sampling these quantities. Furthermore, there is an element of uncertainty and subjectivity in the IBTrACS ET climatology.

With the exception of April, which comparatively has too many simulated TCs and ET events, the seasonality in the number of WNP ET events simulated by MPAS-A compares well with IBTrACS; there is an increase in ET frequency through the beginning of the TC season, reaching a maximum in August, and declining thereafter (Figs. 5b,d). For the MPAS-A simulations, the highest fraction of TCs undergoing ET occurs in June; however, May, July-September, and November also have relatively high percentages. The simulated fraction of ET events is lowest in December and October (Fig. 5b). The IBTrACS ET percentages over the 10 simulation years are also highest in May, June, August, and September, and lowest in December (Fig. 5d). One 
a)

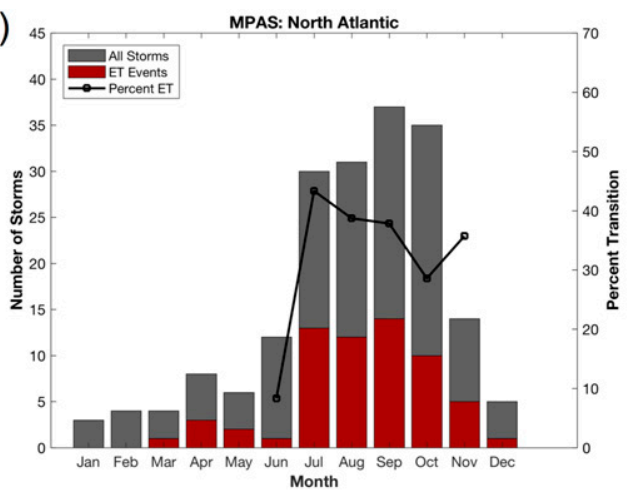

c)

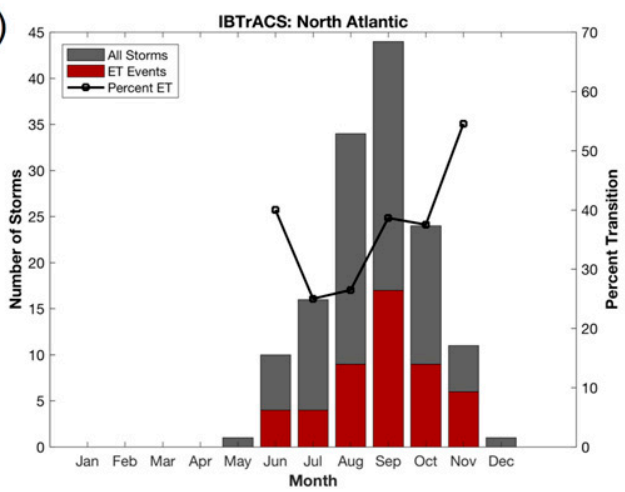

b)

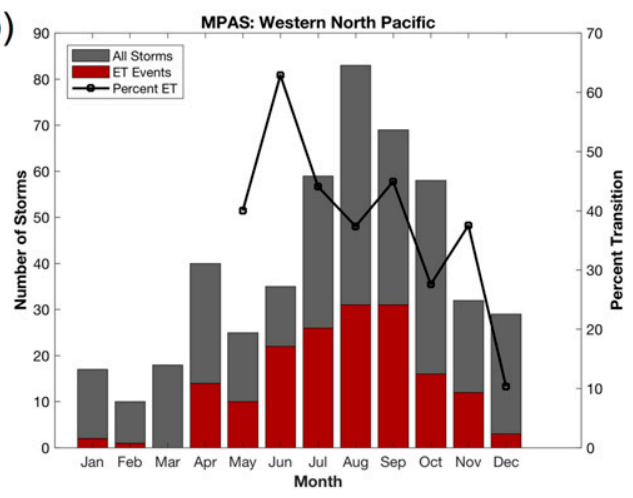

d)

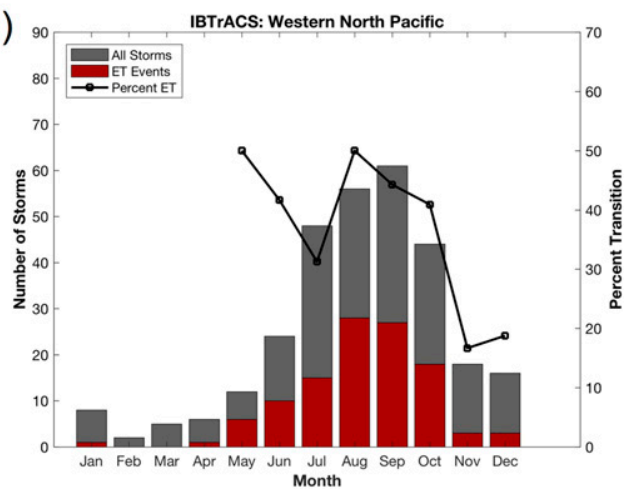

FIG. 5. Total number of TCs (gray bars), ET events (red bars), and percent of TCs that undergo transition (black line) per month over the 10 simulation years in the (left) North Atlantic and (right) western North Pacific for (a),(b) present-day MPAS-A simulations and (c),(d) IBTrACS. Unnamed storms are excluded from IBTrACS counts. Percent transition is only calculated for months with at least 10 storms in both datasets.

of the largest discrepancies between the simulated and observed seasonality of percent transition for the WNP occurs in the late spring/early summer, when the fraction of TCs undergoing ET declines from May to June in IBTrACS, but increases over the same period in the MPAS-A simulations. Additionally, IBTrACS shows a consistent decrease in ET percentage from August through November; the MPAS-A simulations, with a local maximum occurring in November, do not. As with the NATL, uncertainty in the WNP due to sampling errors is large, and variations in the seasonality of percent transition are apparent throughout the literature. One consistent pattern for the WNP, however, is a peak in ET percentage occurring around May-June and a secondary maximum occurring in September or October (Kitabatake 2011; Studholme et al. 2015; Bieli et al. 2019). This same pattern is evident in the MPAS-A simulations (Fig. 5b), albeit with a tertiary maximum in November.

\section{b. Location of extratropical transition}

Upon initial visual inspection, there does not appear to be a systematic latitudinal difference in the location of ET completion between IBTrACS and MPAS-A (Figs. 6a,b). The tracks of ET events in the MPAS-A simulations extend farther east relative to IBTrACS, particularly in the WNP, leading to an apparent larger zonal variation in the location of ET completion (Figs. 6a,b). This may be attributable to differences in how ET events are identified between our simulations and in the IBTrACS dataset. Because we categorize cyclones into basins based on genesis location, there are a small number of storms in the MPAS-A simulations that generate in the NATL, but propagate into the ENP. However, these storms represent a small fraction of the total ET events $(<5 \%)$ and therefore should not significantly influence our results.

Comparison of the median latitude and longitude of ET completion for all ET events over the ten simulation years quantitatively highlights potential biases. Generally, the distributions of ET completion location compare well between IBTrACS and MPAS-A (Figs. 6c,d). In the WNP basin, simulated MPAS-A ET occurs slightly farther south $\left(\right.$ by $\left.\sim 1^{\circ}\right)$, but the variability in this difference is large (Table 3). Eastward shifts in simulated ET location 

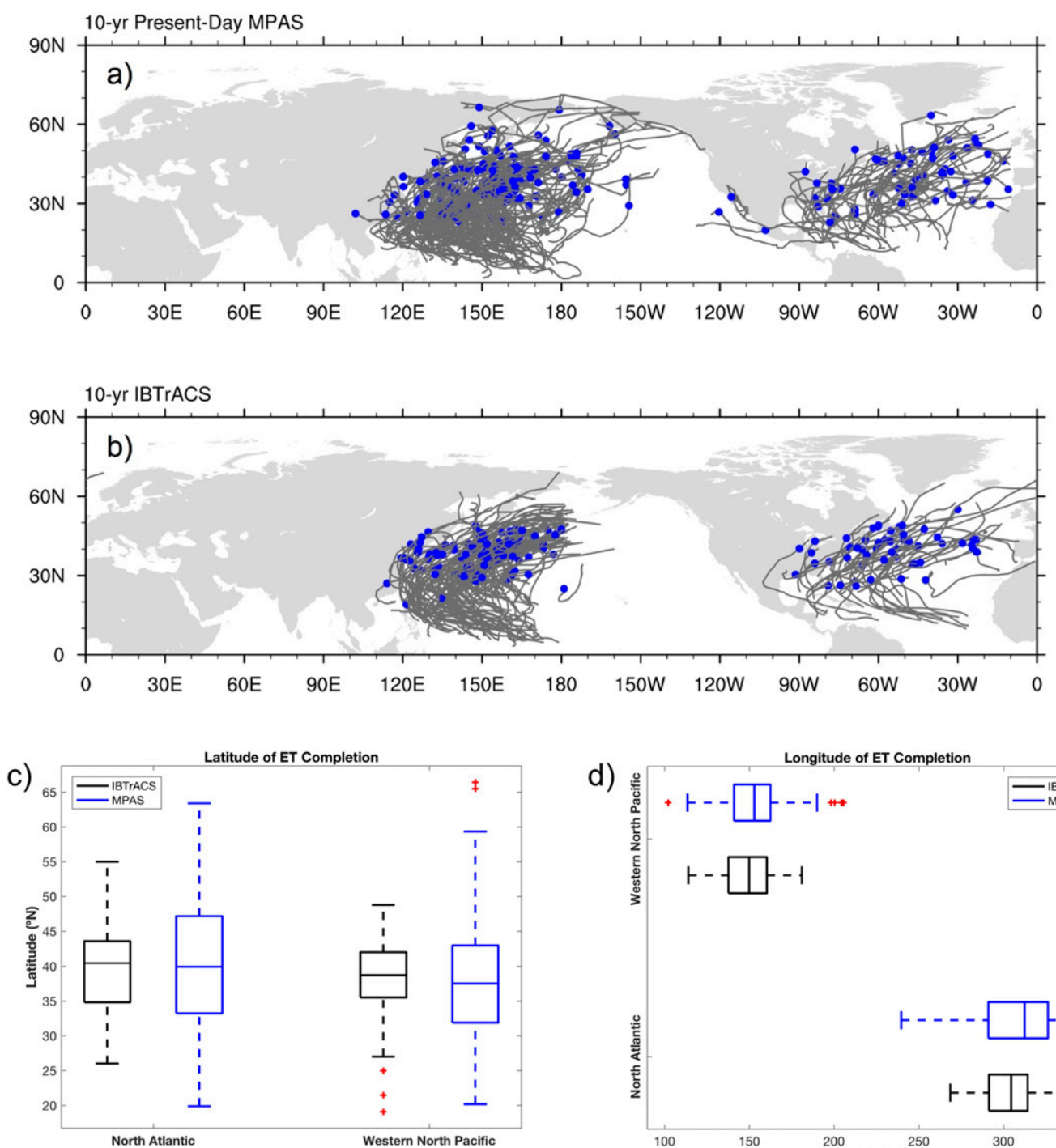

d)

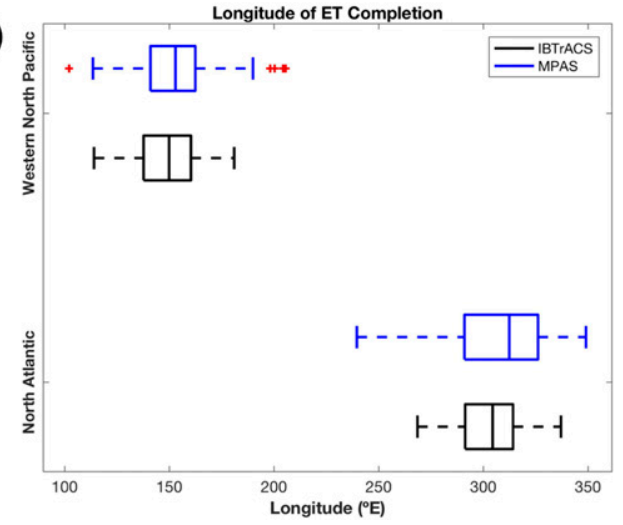

FIG. 6. Tracks for all ET events for the (a) present-day MPAS-A simulations and (b) IBTrACS over the 10 simulation years. Blue circles indicate the location of ET completion. Boxplots of (c) latitude $\left({ }^{\circ} \mathrm{N}\right)$ and (d) longitude $\left({ }^{\circ} \mathrm{E}\right)$ of ET completion for all ET events over the 10 simulation years. Statistics for IBTrACS (MPAS-A) are shown in black (blue).

are apparent in both basins, by $8^{\circ}$ in the NATL and $3^{\circ}$ in the WNP; this difference in the NATL is more robust (Table 3). Overall, the MPAS-A simulations present a larger amount of variation in ET location relative to IBTrACS (Fig. 6). Zarzycki et al. (2017) also showed a larger range in the location of ET in their model simulations compared to reanalyses, particularly with regard to the longitude of ET completion (their Fig. 9), in part attributed to a positive bias in ET duration. Differences between the automated ExTraTrack and the subjective information that goes into IBTrACS also likely contribute to the differences evident in Fig. 6 (see Zarzycki et al. 2017, their section 2.1).

\section{Simulated future changes in extratropical transition climatology}

a. Background environment

\section{1) VERTICAL WIND SHEAR}

Large amounts of vertical wind shear are detrimental to TC development and intensification (e.g., Merrill 1988; DeMaria 1996; Vecchi and Soden 2007, and references therein). Using a set of GCMs under the IPCC Fourth Assessment Report (AR4) midrange A1B emissions scenario, Vecchi and Soden (2007) found significant increases in vertical wind shear in the 
TABLE 3. Median location of ET for TCs that undergo transition in the NATL and WNP basins over the 10 simulation years for IBTrACS and for present-day MPAS-A simulations. The $p$ values are reported from comparing the distributions using the Wilcoxon rank sum statistical significance test. Italicized (bold) values indicate statistical significance at the $90 \%$ (95\%) confidence level.

\begin{tabular}{cccc}
\hline \hline Basin & Data source & $\begin{array}{c}\text { Median } \\
\text { latitude }\left({ }^{\circ} \mathrm{N}\right)\end{array}$ & $\begin{array}{c}\text { Median } \\
\text { longitude }\left({ }^{\circ} \mathrm{E}\right)\end{array}$ \\
\hline NATL & IBTrACS & 40 & 305 \\
& MPAS-A & 40 & 313 \\
& $p$ value & 0.80 & 0.08 \\
WNP & IBTrACS & 39 & 150 \\
& MPAS-A & 38 & 153 \\
& $p$ value & 0.17 & 0.15 \\
\hline
\end{tabular}

NATL basin over the TC season (June-November) by the end of the twenty-first century. Haarsma et al. (2013) and Liu et al. (2017), on the other hand, using GCM output from the IPCC AR5 RCP4.5 emissions scenario, found a reduction in wind shear magnitude throughout most of the NATL over the same time period.

Here, we compute the magnitude of vertical wind shear using the vector difference between monthlymean winds at the $850-$ and $200-\mathrm{hPa}$ levels. Using monthly-mean winds rather than daily winds in this calculation should not produce drastically different results (Vecchi and Soden 2007). The general patterns of climatological monthly vertical wind shear averaged over June-November are comparable between presentday and future climates; maxima off the East Coast of North America, over the northern Pacific, and off the western coast of Africa are apparent in both simulations (Fig. 7a). However, future changes in magnitude are clearly evident (Fig. 7b).

In the NATL, there are distinct areas with stronger vertical wind shear in the future: the tropical Atlantic between $\sim 0^{\circ}$ and $20^{\circ} \mathrm{N}$, throughout the Caribbean Sea and southern Gulf of Mexico, and at higher latitudes across the North Atlantic (Fig. 7b). Vertical wind shear in the tropical Atlantic increases, on average, by $\sim 1.5 \mathrm{~m} \mathrm{~s}^{-1}$, with maxima between 3 and $3.5 \mathrm{~m} \mathrm{~s}^{-1}$ occurring in some areas. Throughout the Caribbean, vertical wind shear increases by $\sim 2 \mathrm{~m} \mathrm{~s}^{-1}$, on average, with maxima $\sim 4.5-5 \mathrm{~m} \mathrm{~s}^{-1}$. Stronger vertical wind shear in these regions likely acts to inhibit TC activity in the future simulations (e.g., Fig. 5.14 from Torres-Vazquez 2018). On the contrary, vertical wind shear in the subtropical and lower midlatitudes of the NATL basin decreases by an average $\sim 1.2 \mathrm{~m} \mathrm{~s}^{-1}$ in the future simulations, with several areas experiencing reductions between 2 and $3 \mathrm{~m} \mathrm{~s}^{-1}$. This reduction in vertical wind shear is consistent with previous work (e.g., Haarsma et al. 2013; Liu et al. 2017) and implies a more favorable environment for future TC activity in this region. Creating a more supportive environment for TCs in the subtropics likely
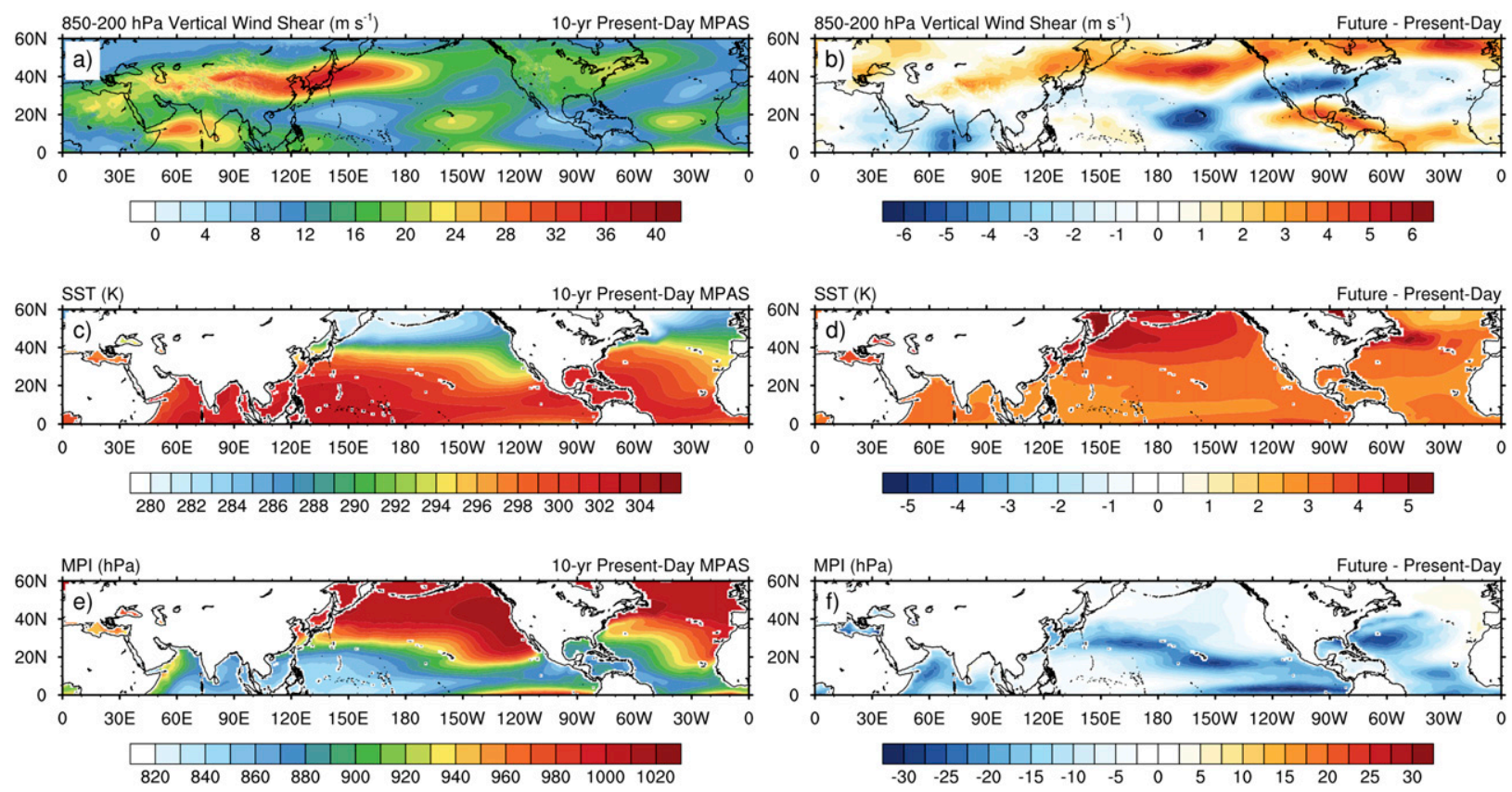

FIG. 7. (a),(b) 10-yr monthly-mean 850-200-hPa vertical wind shear ( $\mathrm{m} \mathrm{s}^{-1}$ ); (c),(d) SST (K); (e),(f) MPI (minimum SLP; hPa) averaged over June-November for (left) present-day simulations and (right) future minus present-day. Shade intervals are every $2 \mathrm{~m} \mathrm{~s}^{-1}$ in (a), $0.5 \mathrm{~m} \mathrm{~s}^{-1}$ in (b), $1 \mathrm{~K}$ in (c), $0.5 \mathrm{~K}$ in (d), $10 \mathrm{hPa}$ in (e), and $2.5 \mathrm{hPa}$ in (f). 
TABLE 4. TC and ET frequency statistics over the 10 simulation years for present-day and future simulations. The range of percent transition $( \pm 1 \sigma)$ from 10005 -yr samples is included in column 5 .

\begin{tabular}{lccccc}
\hline \hline Basin & Climate & Number of TCs & Number of ET events & \% Transition $( \pm 1 \sigma)$ & $\%$ Transition $\sigma$ \\
\hline NATL & Current & 189 & 60 & 32 & $(25-39)$ \\
& Future & 222 & 84 & 38 & $(34-42)$ \\
WNP & Current & 475 & 154 & 32 & 17 \\
& Future & 500 & 161 & $(26-38)$ & 52 \\
& & & & $(30-34)$ \\
\hline
\end{tabular}

increases the chances of TCs reaching the midlatitudes intact, thus making ET more likely in the future simulations in, and downstream of, these locations.

Changes in vertical wind shear throughout the WNP are comparatively less robust. There is an area of slight increase in the tropics, with a limited region to the east of the Marshall Islands showing increases of up to $\sim 1.5-2 \mathrm{~m} \mathrm{~s}^{-1}$ (Fig. 7b). While an increase in vertical wind shear could act to hinder TC development, this change is relatively small, and therefore, may not have a substantial effect on WNP TC activity. A larger area of reduction in vertical wind shear occurs to the north, between $\sim 20^{\circ}$ and $35^{\circ} \mathrm{N}$. Here, vertical wind shear is reduced by $\sim 1.2 \mathrm{~m} \mathrm{~s}^{-1}$ on average, with a maximum of $\sim 2-2.5 \mathrm{~m} \mathrm{~s}^{-1}$ toward the eastern portion of the basin. This magnitude of vertical wind shear decrease is comparable to the subtropical NATL, but does not extend as far poleward. Therefore, while a reduction in subtropical wind shear could raise the chances for WNP TCs to undergo ET in the future simulations, it is possible this effect may be greater in the NATL.

\section{2) SEA SURFACE TEMPERATURES}

It is expected that SSTs will continue to increase under future climate conditions, which would further contribute to an environment favorable for sustained TC activity and, therefore, ET. Changes in SST are fairly similar between the two basins (Fig. 7d). Both the NATL and WNP show overall increased SSTs, and exhibit a warming maximum north of Gulf Stream and Kuroshio, respectively. This enhanced warming could contribute to a tendency for TCs to retain tropical characteristics, such as a warm core structure, to higher latitudes, or to reach peak intensity at higher latitudes (e.g., Kossin et al. 2016; Shen et al. 2018), which can aid in the survival of TCs in the midlatitudes and therefore increase the chance of ET. Additionally, the amount of warming is comparable between the two areas; on average across the basins, SSTs increase $\sim 3 \mathrm{~K}$ in both regions. Relative to the NATL, the zone of midlatitude vertical wind shear increase in the WNP is found at lower latitudes, which could counteract the aforementioned SST influence there.

\section{3) MAXimum POTENTIAL INTENSITY}

Comparison of the maximum potential intensity (MPI; Emanuel 1995) fields shows a reduction in minimum potential SLP (i.e., stronger potential intensity) in the both basins, although this change is more substantial in the NATL (Fig. 7f). On average over the full NATL and WNP basins, from $0^{\circ}$ to $60^{\circ} \mathrm{N}$, the minimum potential SLP is reduced by $\sim 9$ and $\sim 8 \mathrm{hPa}$ in the future, respectively. Over only the tropical regions, however, there is a $\sim 13-\mathrm{hPa}$ reduction in the minimum potential SLP in the NATL compared to a $\sim 5-\mathrm{hPa}$ decrease in the WNP. As shown in Fig. 7d and discussed above, the change in SST over this time period and region is similar between the two basins, which suggests that another factor, such as changes in convective available potential energy (CAPE), could be a larger contributor to these basin-dependent changes in MPI. Examining the average vertical wind shear, SSTs, and MPI over the primary TC season, when the fraction of TCs undergoing ET is generally highest, gives us a general idea of how favorable an environment is for ET and how that favorability may change in the future. Whether or not an individual TC undergoes ET, however, is largely dependent on the local conditions during the lifetime of the storm.

\section{b. Frequency}

There is an increase in the overall number of simulated TCs in the NATL and WNP in the future simulations (Table 4; Figs. 3b,c). In the NATL, there is a $\sim 18 \%$ increase in the number of TCs from 189 in the present-day simulations to 222 in the future simulations. The WNP experiences a smaller change, a $\sim 5 \%$ increase from 475 present-day TCs to 500 in the future. This increase in TC activity differs from previous work projecting an overall decrease in global TC frequency (e.g., Knutson et al. 2010; Mallard et al. 2013b; Walsh et al. 2015; Bacmeister et al. 2018). Other recent studies, however, have found an increase in TC activity under 

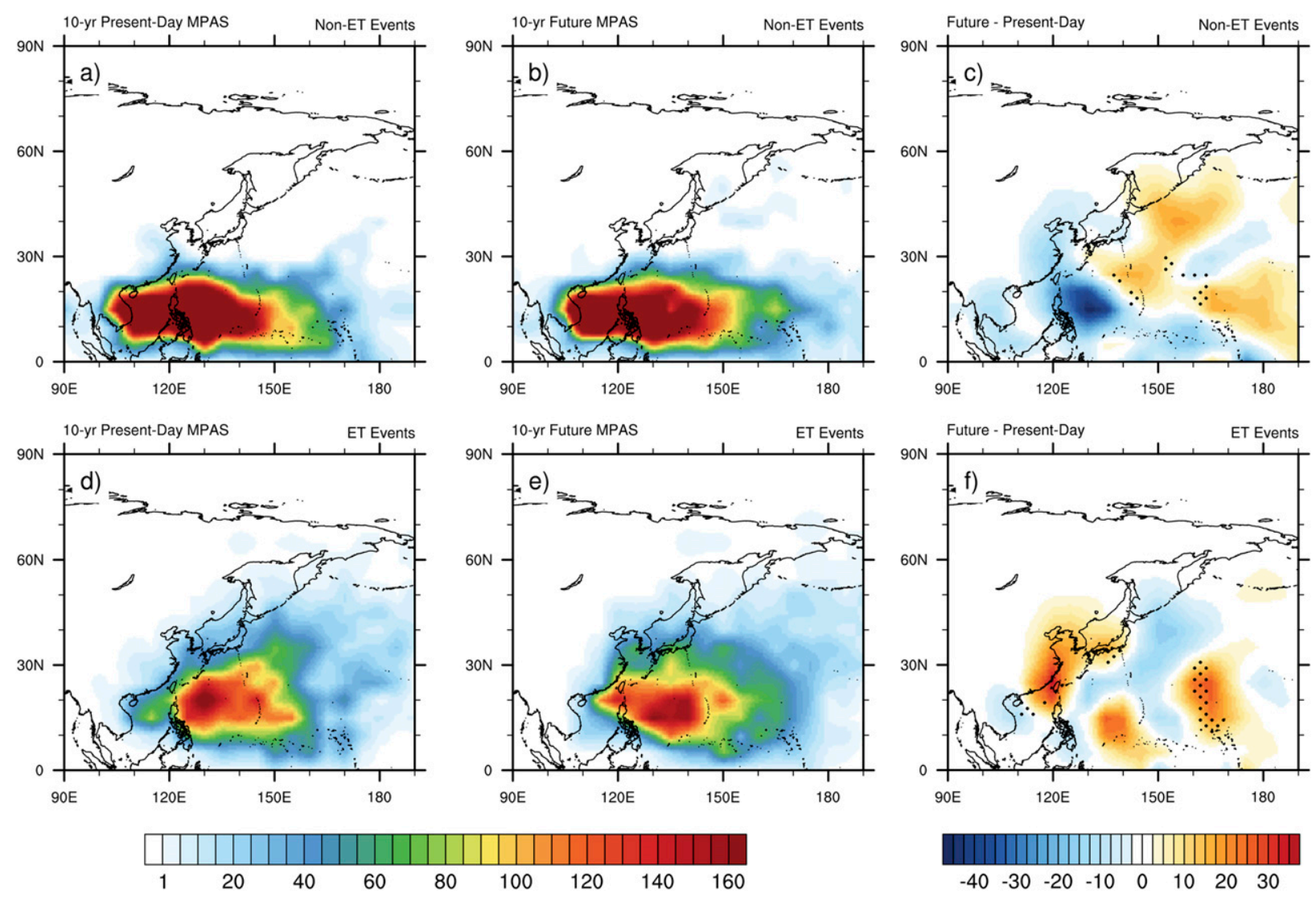

FIG. 8. Track density (number of storms per $5^{\circ} \times 5^{\circ}$ box) of (a)-(c) non-ET and (d)-(f) ET events over the 10 simulation years in the WNP for the (left) present-day simulations, (middle) future simulations, and (right) future minus present-day. Shade interval is 2.5 counts in (c) and (f) and 5 counts in all other panels. Stippling in (c) and (f) indicates where the percent change in the number of events per year is at least $50 \%$. Stippling is restricted to where there is at least \pm one storm per year.

future climate conditions (e.g., Emanuel 2013; Korty et al. 2017; Zhang et al. 2017; Bhatia et al. 2018), indicating that a consensus has not yet been reached on this issue.

The number of ET events in the NATL increases by $\sim 40 \%$ in the future simulations, from 60 events to 84 events. The fraction of TCs that undergo ET in the NATL is also higher in the future; $\sim 38 \%$ of TCs undergo ET in the future simulations compared to $\sim 32 \%$ in the present-day (Table 4). A higher percentage of ET events in the future NATL is consistent with the results discussed above; reduced subtropical vertical wind shear, warmer SSTs, and stronger MPI values create an environment more conducive to ET in the future simulations. Comparison of the average percent transition for 1000 five-year samples between current and future simulations suggests that this increase in ET percentage in the North Atlantic is a robust result (not shown). There are $\sim 5 \%$ more ET events in the WNP in the future, but the fraction of TCs that undergo ET is similar in present-day and future climates (Table 4). Even though environmental conditions are also more favorable for ET in the WNP basin in the future (Fig. 7), we see little to no change in ET percentage. Both basins have a smaller standard deviation of percent transition in the future climate simulations indicating less interannual variability in the future; thus, future TCs appear to be undergoing ET more consistently year to year. The seasonal cycles of ET in both NATL and WNP basins are largely unchanged in the future simulations with a general increase in frequency through the beginning of the TC season, a peak in late summer/early autumn, and a decrease in frequency thereafter (Michaelis 2019, their Fig. 4.5).

\section{c. Location}

Generally, in both the present-day and future simulations, track-density differences suggest that non-ET events in the WNP exhibit tracks that are more zonally oriented relative to those for ET cases (Figs. 8a,b,d,e). The differences between track density patterns of nonET and ET events in the NATL are less distinct; both 

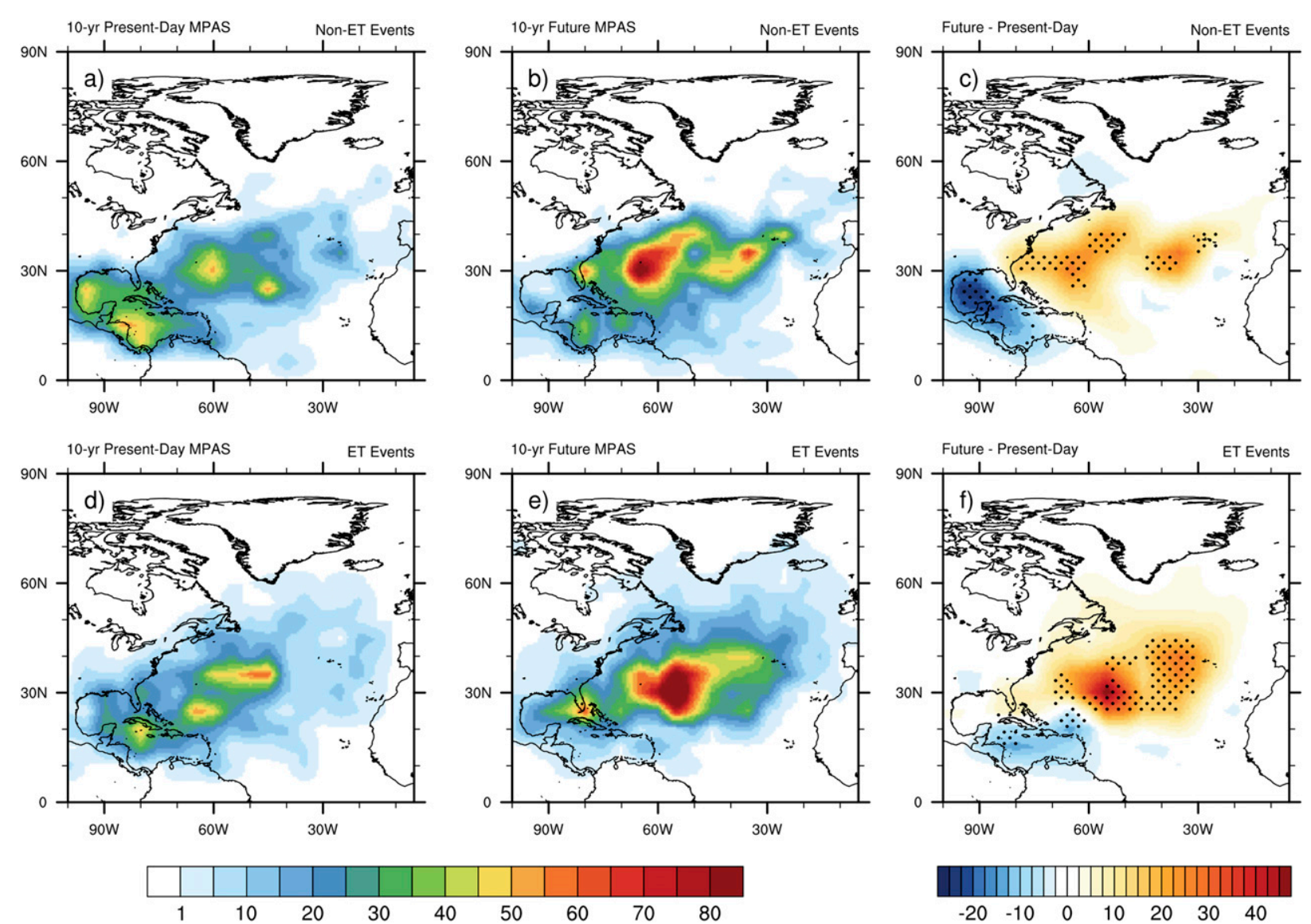

FIG. 9. Track density (number of storms per $5^{\circ} \times 5^{\circ}$ box) of (a)-(c) non-ET and (d)-(f) ET events over the ten simulation years in the NATL for the (left) present-day simulations, (middle) future simulations, and (right) future minus present-day. Shade interval is 2.5 counts in (c) and (f), and 5 counts in all other panels. Stippling in (c) and (f) indicates where the percent change in the number of events per year is at least $50 \%$. Stippling is restricted to where there is at least \pm one storm per year.

non-ET and ET events occur throughout the basin, although the northern edge of the track density for ET events does extend farther poleward (Figs. 9a,b,d,e).

In the NATL, there is a clear increase in both non-ET and ET events around $30^{\circ}-40^{\circ} \mathrm{N}$ in the future simulations (Figs. 9c,f). This increase, coupled with a reduction in TC activity in the Gulf of Mexico that is primarily exhibited by non-ET events (Fig. 9c), suggests a potential eastward shift in NATL storm activity. Haarsma et al. (2013) and Liu et al. (2017) also indicate a possible eastward shift in future NATL TC activity due to warming SSTs. Our simulations show increased vertical wind shear over the Gulf of Mexico and the Caribbean (Fig. 7b) as an additional factor contributing to reduced TC activity in these areas.

The WNP climate change signal in storm location is less clear (Figs. 8c,f). There is an increase in the frequency of non-ET events east of Japan as well as an area of track density increase farther east into the basin, around $180^{\circ} \mathrm{E}$ (Fig. 8c). These increases, coupled with a reduction in activity of non-ET events northeast of the Philippines in the Philippine Sea (Fig. 8c), suggest a potential northeast shift of storm activity in the projected future simulations. ET events, on the other hand, show a slight reduction in activity east of Japan and increases along the east coast of China, over Taiwan and Japan, and east of the Philippines (Fig. 8f). While the changes in the overall number of TCs and ET events in the WNP are small (Table 4), there are potential shifts in where storms occur. However, the track density differences in the WNP are noisier (Fig. 8) and therefore, less robust than the signals in the NATL (Fig. 9), and should be interpreted accordingly.

There is a clear northward shift, and slight eastward extension, in the location of ET onset and completion in the NATL in the future simulations (Figs. 10c,f). Again, the signal in the WNP is not as robust. Here, the ET onset density shows two areas of slightly positive change, one to the west of Japan over North Korea and South Korea, and the other toward the southeastern portion of 

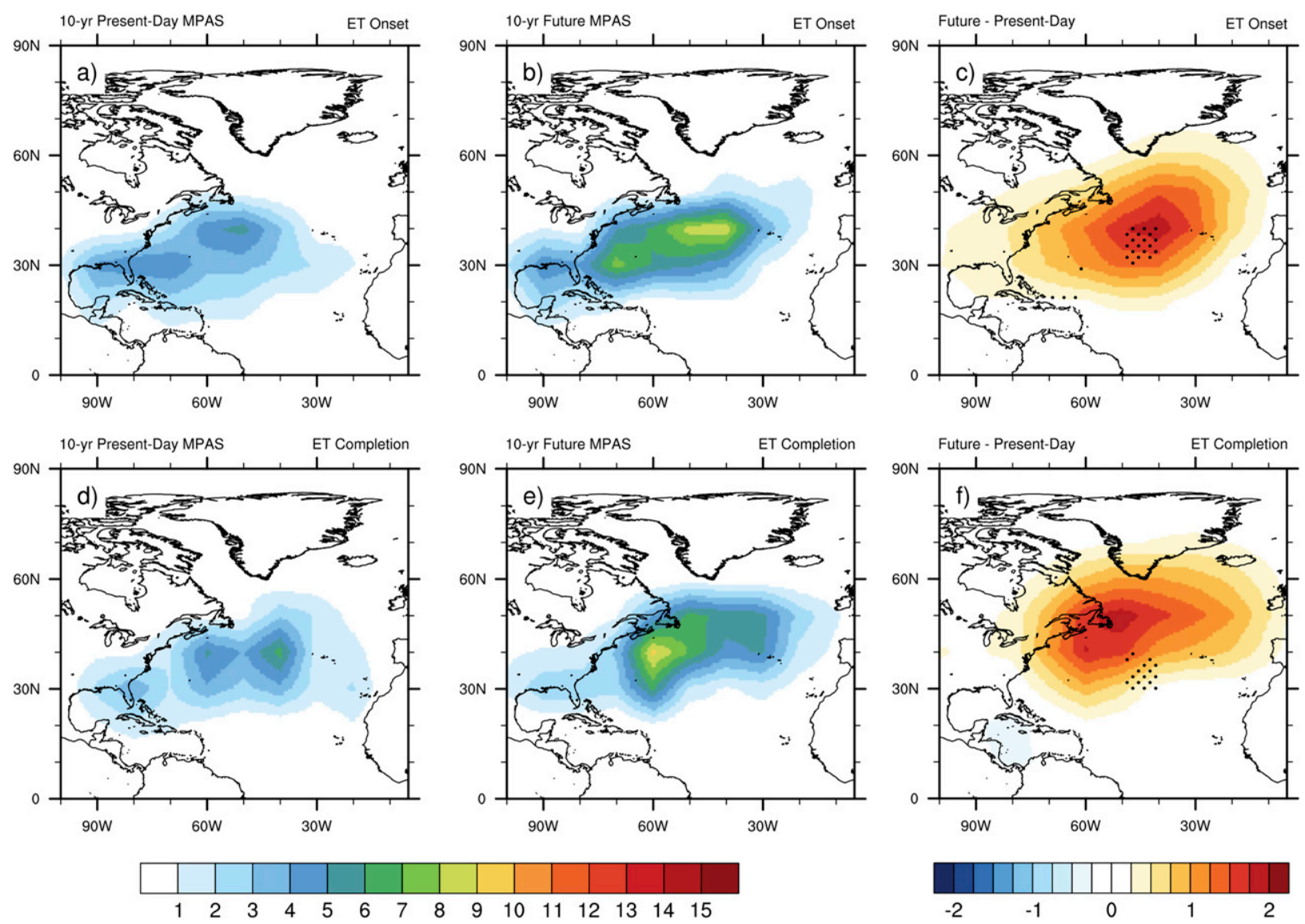

FIG. 10. (a)-(c) ET onset and (d)-(f) ET completion density (number of storms per $10^{\circ} \times 10^{\circ}$ box) over the 10 simulation years in the NATL for the (left) present-day simulations, (middle) future simulations, and (right) future minus present-day. Shade interval is 1 count in the left and middle columns and 0.5 count in the right column. Stippling in (c) and (f) indicates where the percent change in the number of events per year is at least $50 \%$. Stippling is restricted to where there is at least \pm 1 storm per year.

the basin at $\sim 20^{\circ} \mathrm{N}, 165^{\circ} \mathrm{W}$ (Fig. 11c). The difference in ET completion density shows a similar pattern; there are areas of increase in the East China Sea and in the southeastern portion of the basin with a region of decreasing density in between (Fig. 11f). The prevalence of noise in the differences fields for the WNP indicates that results should be interpreted with caution.

The median latitudes of ET onset and completion in the NATL occur $\sim 4^{\circ}$ and $\sim 5^{\circ}$ farther north in the future simulations, respectively (Table 5). These northward shifts are consistent with a significant poleward shift in the latitude of TC genesis and location of lifetime maximum intensity for all NATL TCs in our simulations (Torres-Vazquez 2018). ET onset and completion in the NATL occur farther east in the future simulations by $\sim 6^{\circ}$ and $\sim 1^{\circ}$, respectively; however, these differences exhibit a larger amount of variance (Table 5). ET onset and completion locations in the WNP show slight northwest and southwest shifts in the future, respectively (Table 5). Due to the dipole pattern exhibited by the changes in ET onset and completion location in the WNP (Figs. 11c,f), it is unsurprising that these differences are highly variable (Table 5). Likewise, there is not a significant shift in the location of TC genesis or lifetime maximum intensity for WNP TCs as a whole (TorresVazquez 2018).

\section{d. Intensity and cyclone phase space}

NATL ET events in the future simulations are generally stronger at each stage of the cyclone life cycle (Table 6; Fig. 12a). The shifts toward lower SLPs at ET completion and toward stronger posttransition storms are the most robust (Table 6). The minimum SLP reached by ET events in WNP during the tropical phase is significantly lower by $\sim 12 \mathrm{hPa}$ in the future simulations (Table 6). Differences in intensity between the present-day and future storms at the other life cycle stages, however, are comparatively small (Table 6; Fig. 12b). 

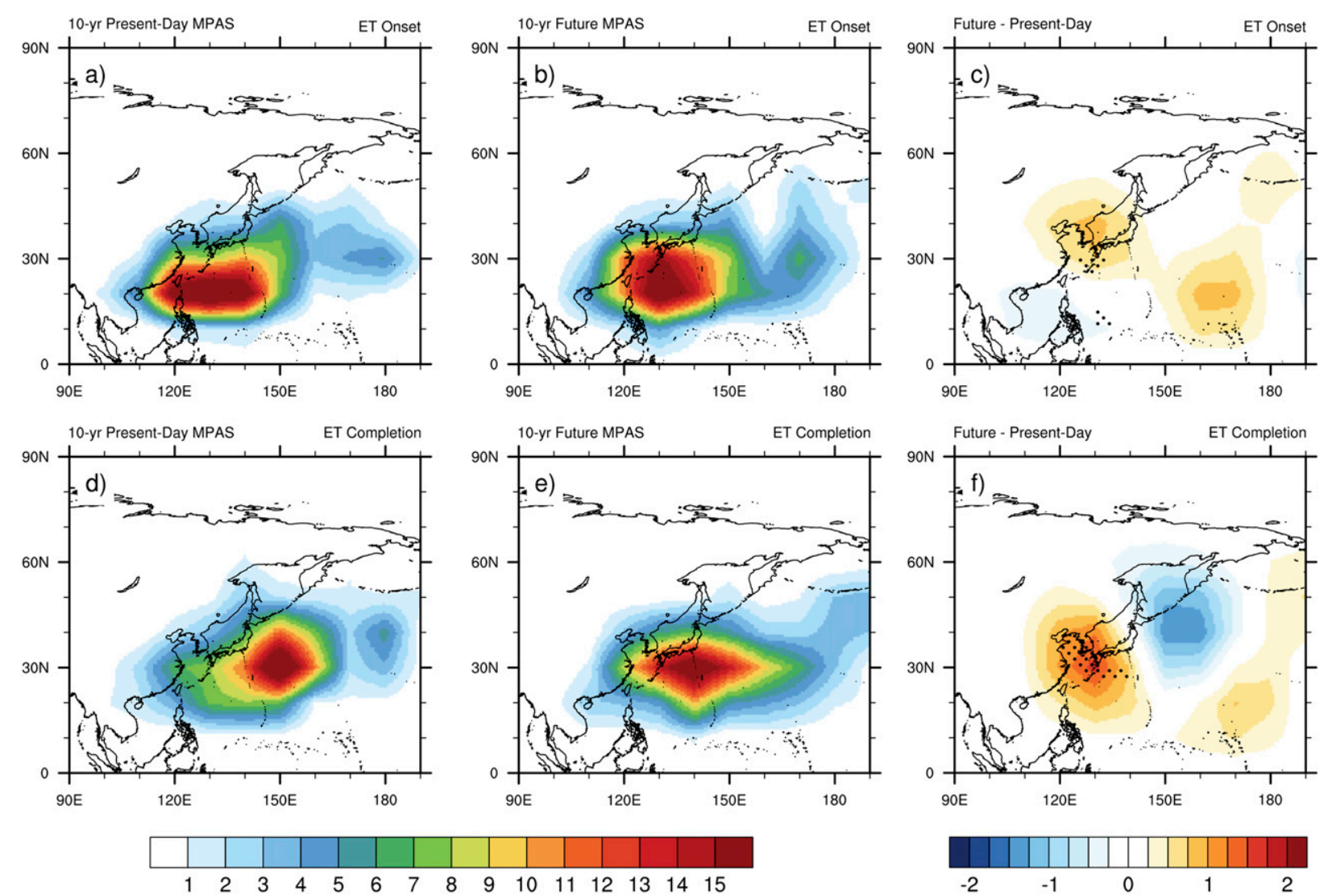

FIG. 11. (a)-(c) ET onset and (d)-(f) ET completion density (number of storms per $10^{\circ} \times 10^{\circ}$ box) over the 10 simulation years in the WNP for the (left) present-day simulations, (middle) future simulations, and (right) future minus present-day. Shade interval is 1 count in the left and middle columns and 0.5 count in the right column. Stippling in (c) and (f) indicates where the percent change in the number of events per year is at least $50 \%$. Stippling is restricted to where there is at least \pm 1 storm per year.

Present-day composite CPS diagrams for all NATL ET events (Figs. 13a,e) are comparable to Zarzycki et al. (2017, their Fig. 11). The general structure for both present-day and future events is similar; storms spend the most time as tropical systems (i.e., frequencies are highest in the bottom-right quadrant of the top row and the top-right quadrant of the bottom row). Figures 13c, 13d, $13 \mathrm{~g}$, and $13 \mathrm{~h}$ primarily show shifts toward larger - VLT in the bottom-right and top-right quadrants for future storms, respectively. This indicates that, as tropical systems, future NATL ET events have stronger lower-level warm cores. A stronger low-level warm-core structure in future NATL ET events is consistent with expected increases in moisture and enhanced latent heat release, and is in agreement with the case-study findings of Jung and Lackmann (2019). Stronger warm cores could be a contributing factor in a higher fraction of NATL TCs undergoing ET in the future simulations; TCs with an

TABLE 5. Median location of ET onset and completion for the NATL and WNP basins. The $p$ values are based on a Wilcoxon rank sum statistical significance test. Italicized (bold) values indicate statistical significance at the $90 \%$ (95\%) confidence level.

\begin{tabular}{|c|c|c|c|c|c|}
\hline Basin & Climate & $\begin{array}{c}\text { Median latitude }\left({ }^{\circ} \mathrm{N}\right) \\
\text { of ET onset }\end{array}$ & $\begin{array}{l}\text { Median longitude }\left({ }^{\circ} \mathrm{E}\right) \\
\text { of ET onset }\end{array}$ & $\begin{array}{c}\text { Median latitude }\left({ }^{\circ} \mathrm{N}\right) \\
\text { of ET completion }\end{array}$ & $\begin{array}{l}\text { Median longitude }\left({ }^{\circ} \mathrm{E}\right) \\
\text { of ET completion }\end{array}$ \\
\hline \multirow[t]{3}{*}{ North Atlantic } & Current & 35 & 303 & 40 & 313 \\
\hline & Future & 39 & 309 & 45 & 314 \\
\hline & $p$ value & 0.003 & 0.18 & 0.001 & 0.41 \\
\hline \multirow[t]{3}{*}{ Western North Pacific } & Current & 31 & 143 & 38 & 153 \\
\hline & Future & 31 & 142 & 36 & 150 \\
\hline & $p$ value & 0.72 & 0.99 & 0.37 & 0.61 \\
\hline
\end{tabular}


TABLE 6. Median intensity (SLP; hPa) at various stages of the cyclone life cycle. The $p$ values are based on a Wilcoxon rank sum statistical significance test. Italicized (bold) values indicate statistical significance at the $90 \%$ (95\%) confidence level.

\begin{tabular}{|c|c|c|c|c|c|c|}
\hline Basin & Climate & $\begin{array}{l}\text { Median minimum } \\
\text { tropical SLP }(\mathrm{hPa})\end{array}$ & $\begin{array}{l}\text { Median SLP }(\mathrm{hPa}) \\
\text { 12-h prior to ET onset }\end{array}$ & $\begin{array}{c}\text { Median SLP } \\
(\mathrm{hPa}) \text { at ET onset }\end{array}$ & $\begin{array}{l}\text { Median SLP }(\mathrm{hPa}) \\
\text { at ET completion }\end{array}$ & $\begin{array}{l}\text { Median minimum } \\
\text { post-ET SLP }(\mathrm{hPa})\end{array}$ \\
\hline \multirow[t]{3}{*}{ North Atlantic } & Current & 975 & 991 & 992 & 1000 & 1000 \\
\hline & Future & 969 & 988 & 989 & 997 & 994 \\
\hline & $p$ value & 0.42 & 0.29 & 0.22 & 0.07 & 0.04 \\
\hline \multirow{3}{*}{$\begin{array}{l}\text { Western North } \\
\text { Pacific }\end{array}$} & Current & 953 & 979 & 981 & 997 & 996 \\
\hline & Future & 941 & 980 & 983 & 995 & 995 \\
\hline & $p$ value & 0.02 & 0.57 & 0.57 & 0.35 & 0.50 \\
\hline
\end{tabular}

enhanced warm core structure are likely able to survive in unfavorable conditions for longer periods of time, thus increasing the probability of undergoing ET (Hart et al. 2006). The lack of substantial changes in the other CPS quadrants suggests that, while the structure of ET events is altered during the TC phase, the overall ET process is largely unchanged in the future simulations.

Similar to NATL ET events, ET events in the WNP also spend most of their life as tropical systems (Figs. 14a,b,e,f). Unlike NATL storms, though, there are not drastic differences in the composite CPS diagrams between present-day and future storms. The bottom-right and top-right quadrants of Figs. $14 \mathrm{c}$ and $14 \mathrm{~g}$ show a dipole pattern in the difference field, indicating that some storms experience stronger warm cores in the future simulations, while others experience weaker warm cores. Similarly, the pattern in Fig. 14c shows increases in the frequency of both more positive and more negative $B$ values, rather than a systematic shift in one direction. These changes in symmetry are consistent with the pattern of track density change for WNP ET events (Fig. 8f), which shows both poleward and equatorward increases in storm activity, suggesting a greater geographic range of storm activity in the future simulations.

\section{Summary and conclusions}

Previous studies that have examined how transitioning TCs could be affected by climate change have found evidence for an increase in the percentage of NATL TCs undergoing ET (Haarsma et al. 2013; Baatsen et al. 2015; Liu et al. 2017). This is apparently due to a more favorable background environment, an eastward and poleward extension of the TC development region, and/or an increase in TC strength. On the contrary, a case study by Ito et al. (2016) showed that weakened baroclinicity in the WNP created an environment less favorable for ET in the future. Our results are consistent with prior work for the NATL, finding increases in ET activity, intensity, and transition
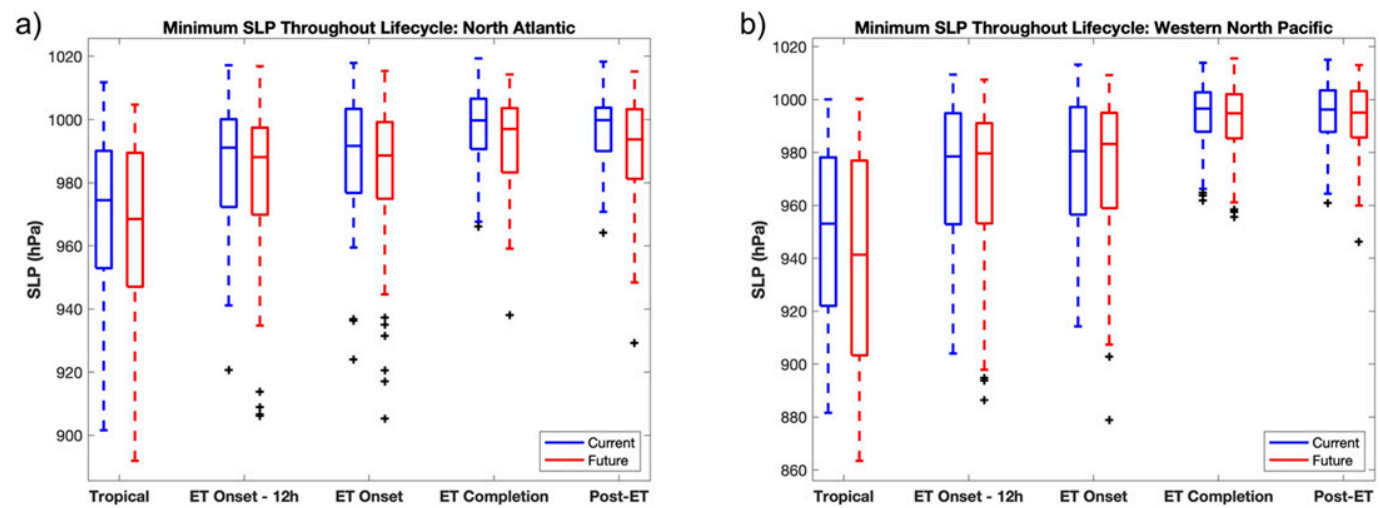

FIG. 12. Boxplots showing the minimum SLP (hPa) reached as a tropical cyclone before ET onset, $12 \mathrm{~h}$ prior to ET onset, at the time of ET onset, at the time of ET completion, and as an extratropical cyclone after ET completion for all storms over the ten simulation years in the (a) North Atlantic and (b) western North Pacific basins. Presentday (future) distributions are shown in blue (red). The bottom whisker indicates the maximum intensity (e.g., lowest minimum SLP). The top whisker indicates the minimum intensity (e.g., highest minimum SLP). The bottom, middle, and top lines associated with each box represent the 75 th, 50th, and 25 th percentile intensity. The black asterisks represent outliers that fall outside of $\pm 2.7 \sigma$ range. 

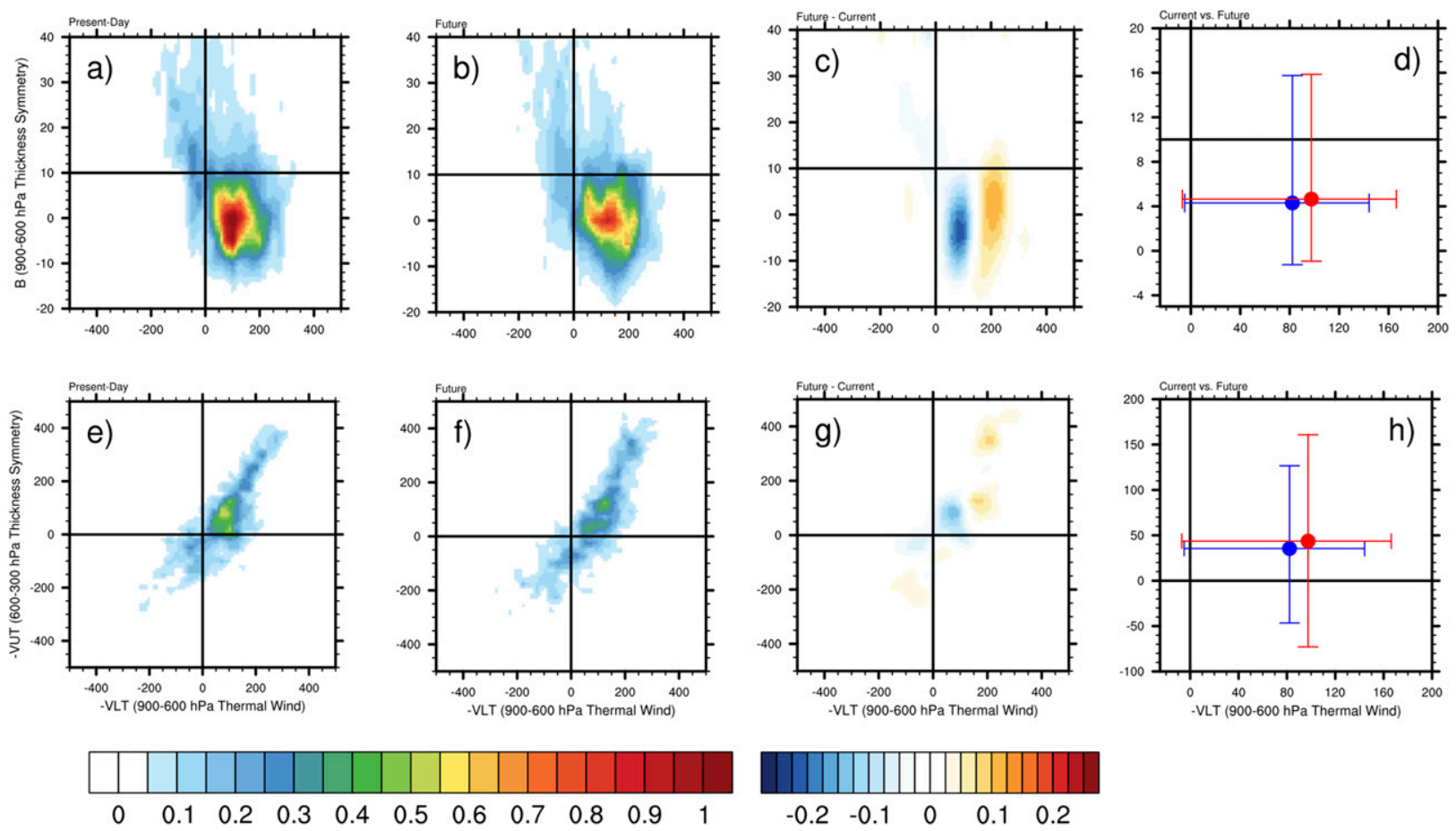

FIG. 13. Cyclone phase space frequency diagrams for all NATL ET events in the (a),(e) present-day simulations, (b),(f) future simulations, and (c),(g) future minus present-day, showing (top) - VLT vs $B$ and (bottom) - VLT vs - VUT. Frequencies in (a),(b) and (e),(f) are normalized by the number of storms. (d),(h) Boxplots where the filled circle indicates the median of the distributions. Present-day (future) distributions are shown in blue (red). The bottom and top bounds in (d) and (h) represent the 25 th and 75 th percentile $B$ (in the top row) and - VUT (in the bottom row). The left and right bounds in (d) and (h) represent the 25th and 75th percentile -VLT in both rows.

percentage, and a northward shift in ET events for that basin.

The current generation of GCMs are too coarse to resolve TCs and consequently cannot represent ET. Therefore, to examine how ET may be affected by climate change, we conduct a novel set of model simulations using MPAS-A in present-day and future environments that are designed to maximize our ability to analyze changes in high-impact weather systems, including ET events (Michaelis et al. 2019). Owing to computational expense, our simulations are limited to a single set of physics and a single future projection scenario (RCP8.5); nevertheless, these simulations are capable of resolving strong TC and ET events, and thus provide a unique opportunity to contribute to our understanding of ET and climate change.

We used the TempestExtremes and ExTraTrack algorithms (Ullrich and Zarzycki 2017; Zarzycki and Ullrich 2017; Zarzycki et al. 2017) to track simulated TC and ET events, and a CPS method to objectively identify ET events. The simulated present-day estimates of percentage of TCs undergoing ET in the NATL and WNP basins are within the observed range of variability (Table 2). Our MPAS-A simulations produce more variation in ET location compared to observations (Fig. 6), but the median location of ET in both basins matches reasonably well (Table 3).

One of the most significant changes in the simulated future ET climatology is that a higher fraction of NATL TCs undergoes ET in the future simulations (Table 4). Environmental factors that potentially contribute to this future increase in ET percentage include reduced vertical wind shear throughout the NATL subtropics (Fig. 7b), warmer SSTs (Fig. 7d), and greater maximum potential intensity (Fig. 7f). Another factor that could contribute to this result is a stronger warm core structure in NATL TCs (Fig. 13), which likely increases the chances of survival in unfavorable environmental conditions, thus increasing the likelihood of ET. Additionally, there is a significant poleward shift in the latitude of TC genesis and location of peak intensity for NATL events in our simulations (Torres-Vazquez 2018), which reduces the distance needed for a TC to travel in an unfavorable environment, and therefore increases the chances of ET. All of these factors increase the likelihood of ET in the NATL and thus are consistent with the simulated increase in ET percentage, and with previous work. This increase in the frequency of ET events holds 

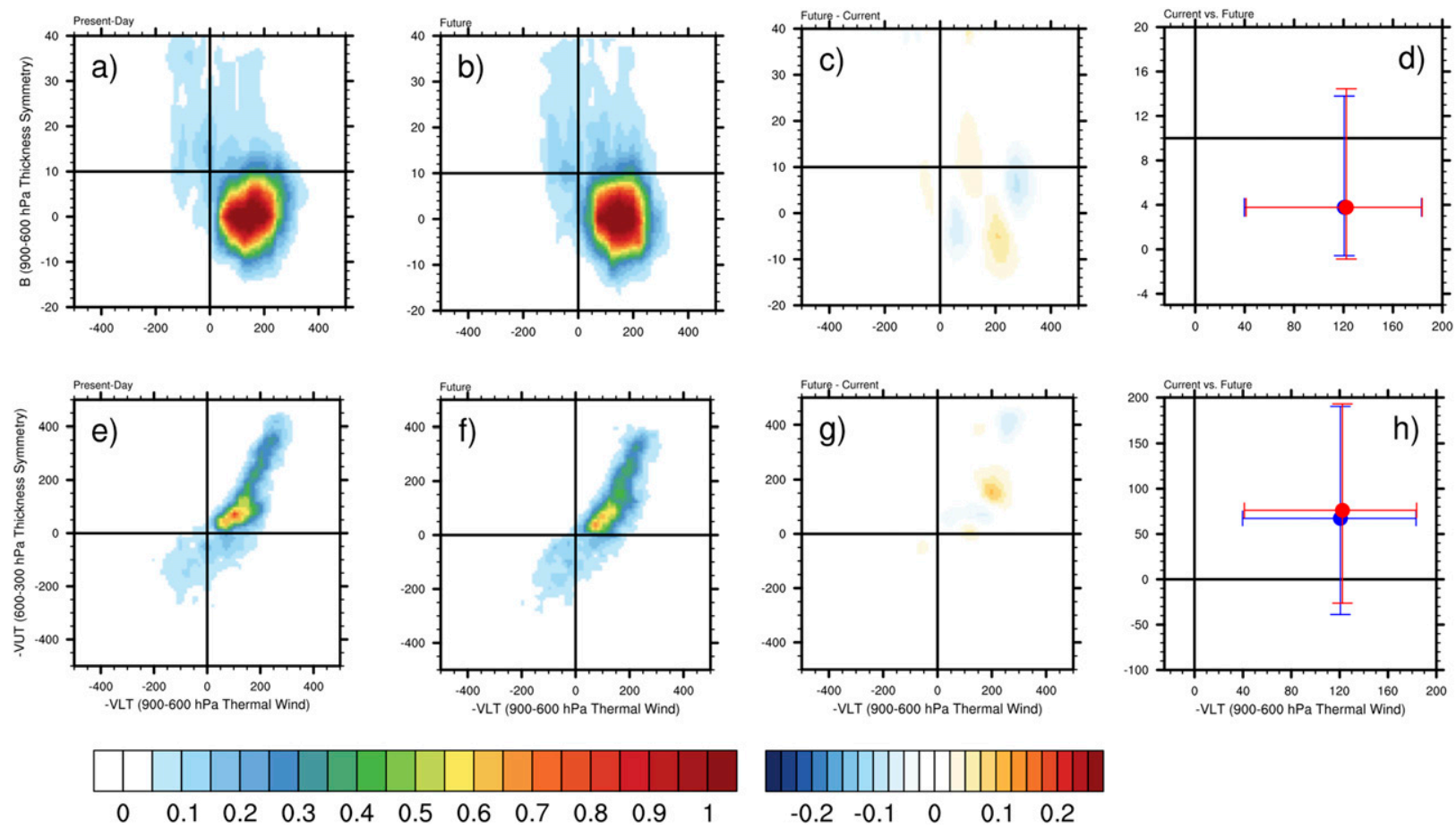

$\begin{array}{lllll}-0.2 & -0.1 & 0 & 0.1 & 0.2\end{array}$

FIG. 14. Cyclone phase space frequency diagrams for all WNP ET events in the (a),(e) present-day simulations, (b),(f) future simulations, and (c),(g) future minus present-day, showing (top) - VLT vs $B$ and (bottom) - VLT vs - VUT. Frequencies in (a),(b) and (e),(f) are normalized by the number of storms. Boxplots are shown in (d) and (h) where the filled circle indicates the median of the distributions. Present-day (future) distributions are shown in blue (red). The bottom and top bounds in (d) and (h) represent the 25 th and 75 th percentile $B$ (in the top row) and -VUT (in the bottom row). The left and right bounds in (d) and (h) represent the 25th and 75th percentile -VLT in both rows.

implications for potential future changes in the Northern Hemispheric ETC climatology, especially during autumn, which is outside of climatological peak of ETC activity; such contributions will be omitted in GCMs and other coarse modeling studies that are unable to capture TCs and ET events. Similar changes in the background environment occur in the WNP (Fig. 7), but there are not significant shifts toward stronger lower-tropospheric warm cores for storms in this basin (Fig. 14) nor is there a change in the location of TC genesis or peak intensity (Torres-Vazquez 2018), resulting in little change in ET percentage for WNP events (Table 4).

Consistent with the shift in TC genesis and lifetime maximum intensity location (Torres-Vazquez 2018), the locations of ET onset and completion in the NATL are also shifted significantly poleward in the future simulations by $4^{\circ}$ and $5^{\circ}$, respectively (Table 5; Fig. 10). Additionally, future NATL ET events are shown to be stronger at later stages of the cyclone life cycle, particularly as post-transition ETCs where the median minimum SLP is $\sim 6 \mathrm{hPa}$ lower (Table 6 ; Fig. 12a). The outflow from ET events can modify midlatitude flow and lead to high-impact weather far downstream from the original TC (e.g., Harr and Dea 2009; Archambault et al. 2013, 2015; Keller et al. 2019); therefore, this shift toward stronger post-transition ETCs implies potentially stronger outflow from future ET events, and consequently, more extreme downstream impacts. These results are also consistent with a case study of Hurricane Irene (2011, NATL) by Jung and Lackmann (2019), who found stronger downstream ridging in future simulations of that event. WNP events, on the other hand, show no significant change in ET location (Table 5; Fig. 11) and are only significantly more intense as tropical systems, where future storms are $\sim 12 \mathrm{hPa}$ stronger (Table 6; Fig. 12b).

Further analysis examining potential changes in the ET process, storm-scale dynamics, and impacts associated with ET events will be the topic of an upcoming paper. Additional future work includes investigating the interannual variability in ET changes (e.g., comparing years with the largest changes to years with the smallest changes), which will help shed light on the primary factors affecting ET in future climate conditions. The results of the simulations presented here are largely consistent with other studies that used different experimental designs, which increases confidence in these results. However, there are several limitations to 
our experimental design that should be addressed in future work. For example, an ensemble approach, either with altered physics choices or initial condition perturbations, would be useful in cross-checking these findings. Our simulations use analyzed SST patterns, and do not include cold-wake feedbacks that are present in observed TCs. Much more could be done to address uncertainty in future projections, including examination of other emissions pathways, or the use of GCM SST clustering methods (e.g., Mizuta et al. 2014), which would take account of variations in GCM SST change patterns. Finally, the ability to run with a $3-\mathrm{km}$ mesh over the TC-active regions, with scale-aware convective parameterization effectively omitting this parameterization there, would allow for even more realistic TC and ET representations.

Acknowledgments. This research was supported by NSF Grants AGS-1546743 and AGS-1560844, awarded to North Carolina State University (NCSU). The National Center for Atmospheric Research (NCAR), sponsored by the National Science Foundation (NSF), made available MPAS-A and the NCAR Command Language (NCL) software. High-performance computing support from Cheyenne (https://doi.org/10.5065/ D6RX99HX) was provided by NCAR's Computational and Information System Laboratory, also sponsored by the NSF. Michael Duda at NCAR provided our custom MPAS grid and additional MPAS support. Chunyong Jung at NCSU provided the CMIP5 GCM ensemble mean data and interpolation codes used in this study. We are indebted to Paul Ullrich and Colin Zarzycki for making the TempestExtremes and ExTraTrack software available, which was extremely helpful in this study. Special thanks to Walter Robinson and Anantha Aiyyer for fruitful discussions during the experimental design and analysis phases of this work, in addition to constructive comments on earlier versions of this manuscript. We are grateful for the insightful comments, suggestions, and constructive criticism provided by two anonymous reviewers. Requests to access the model output from the simulations presented in this manuscript can be sent to the corresponding author.

\section{REFERENCES}

Archambault, H. M., L. F. Bosart, D. Keyser, and J. M. Cordeira, 2013: A climatological analysis of the extratropical flow response to recurving western North Pacific tropical cyclones. Mon. Wea. Rev., 141, 2325-2346, https://doi.org/10.1175/ MWR-D-12-00257.1.

— D. Keyser, L. F. Bosart, C. A. Davis, and J. M. Cordeira, 2015: A composite perspective of the extratropical flow response to recurving western North Pacific tropical cyclones.
Mon. Wea. Rev., 143, 1122-1141, https://doi.org/10.1175/ MWR-D-14-00270.1.

Arnott, J. M., J. L. Evans, and F. Chiaromonte, 2004: Characterization of extratropical transition using cluster analysis. Mon. Wea. Rev., 132, 2916-2937, https://doi.org/10.1175/ MWR2836.1.

Baatsen, M., R. J. Haarsma, A. J. Van Delden, and H. de Vries, 2015: Severe autumn storms in future western Europe with a warmer Atlantic Ocean. Climate Dyn., 45, 949-964, https:// doi.org/10.1007/s00382-014-2329-8.

Bacmeister, J. T., K. A. Reed, C. Hannay, P. Lawrence, S. Bates, J. E. Truesdale, N. Rosenbloom, and M. Levy, 2018: Projected changes in tropical cyclone activity under future warming scenarios using a high-resolution climate model. Climatic Change, 146, 547-560, https://doi.org/10.1007/s10584-016-1750-x.

Bhatia, K., G. Vecchi, H. Murakami, S. Underwood, J. Kossin, 2018: Projected response of tropical cyclone intensity and intensification in a global climate model. J. Climate, 31, 8281-8303, https://doi.org/10.1175/JCLI-D-17-0898.1.

Bieli, M., S. J. Camargo, A. H. Sobel, J. L. Evans, and T. Hall, 2019: A global climatology of extratropical transition. Part I: Characteristics across basins. J. Climate, 32, 3557-3582, https://doi.org/ 10.1175/JCLI-D-17-0518.1.

Booth, J. F., H. E. Rieder, and Y. Kushnir, 2016: Comparing hurricane and extratropical storm surge for the Mid-Atlantic and Northeast Coast of the United States for 1979-2013. Environ. Res. Lett., 11, 094004, https://doi.org/10.1088/1748-9326/11/9/ 094004.

Colle, B. A., J. F. Booth, and E. K. Chang, 2015: A review of historical and future changes of extratropical cyclones and associated impacts along the US East Coast. Curr. Climate Change Rep., 1, 125-143, https://doi.org/10.1007/s40641-015-0013-7.

Davis, C. A., 2018: Resolving tropical cyclone intensity in models. Geophys. Res. Lett., 45, 2082-2087, https://doi.org/10.1002/ 2017GL076966.

- D. A. Ahijevych, W. Wang, and W. C. Skamarock, 2016: Evaluating medium-range tropical cyclone forecasts in uniform- and variable-resolution global models. Mon. Wea. Rev., 144, 4141-4160, https://doi.org/10.1175/MWR-D-16-0021.1.

DeMaria, M., 1996: The effect of vertical shear on tropical cyclone intensity change. J. Atmos. Sci., 53, 2076-2088, https://doi.org/ 10.1175/1520-0469(1996)053<2076:TEOVSO > 2.0.CO;2.

Done, J. M., G. J. Holland, and P. J. Webster, 2011: The role of wave energy accumulation in tropical cyclogenesis over the tropical North Atlantic. Climate Dyn., 36, 753-767, https:// doi.org/10.1007/s00382-010-0880-5.

Donlon, C. J., M. Martin, J. Stark, J. Roberts-Jones, E. Fiedler, and W. Wimmer, 2012: The Operational Sea Surface Temperature and Sea Ice Analysis (OSTIA) system. Remote Sens. Environ., 116, 140-158, https://doi.org/10.1016/j.rse.2010.10.017.

Emanuel, K. A., 1995: Sensitivity of tropical cyclones to surface exchange coefficients and a revised steady-state model incorporating eye dynamics. J. Atmos. Sci., 52, 3969-3976, https://doi.org/10.1175/1520-0469(1995)052<3969:SOTCTS> 2.0.CO;2.

_ 2013: Downscaling CMIP5 climate models shows increased tropical cyclone activity over the 21st century. Proc. Natl. Acad. Sci. USA, 110, 12 219-12224, https://doi.org/10.1073/ pnas.1301293110.

Evans, C., and Coauthors, 2017: The extratropical transition of tropical cyclones. Part I: Cyclone evolution and direct impacts. Mon. Wea. Rev., 145, 4317-4344, https://doi.org/10.1175/ MWR-D-17-0027.1. 
Evans, J. L., and R. E. Hart, 2003: Objective indicators of the life cycle evolution of extratropical transition for Atlantic tropical cyclones. Mon. Wea. Rev., 131, 909-925, https://doi.org/ 10.1175/1520-0493(2003)131<0909:OIOTLC $>2.0$.CO;2.

Frei, C., C. Schär, D. Lüthi, and H. C. Davies, 1998: Heavy precipitation processes in a warmer climate. Geophys. Res. Lett., 25, 1431-1434, https://doi.org/10.1029/98GL51099.

Gentry, M. S., and G. M. Lackmann, 2010: Sensitivity of simulated tropical cyclone structure and intensity to horizontal resolution. Mon. Wea. Rev., 138, 688-704, https://doi.org/10.1175/ 2009MWR2976.1.

Gutman, E. D., and Coauthors, 2018: Changes in hurricanes from a 13-yr convection-permitting pseudo-global warming simulation. J. Climate, 31, 2643-3657, https://doi.org/10.1175/JCLID-17-0391.1.

Haarsma, R. J., W. Hazeleger, C. Severijns, H. Vries, A. Sterl, R. Bintanja, G. J. van Oldenborgh, and H. W. van den Brink, 2013: More hurricanes to hit western Europe due to global warming. Geophys. Res. Lett., 40, 1783-1788, https://doi.org/ 10.1002/grl.50360.

Hara, M., T. Yoshikane, H. Kawase, and F. Kimura, 2008: Estimation of the impact of global warming on snow depth in Japan by the pseudo-global-warming method. Hydrol. Res. Lett., 2, 61-64, https://doi.org/10.3178/hrl.2.61.

Harr, P. A., and R. L. Elsberry, 2000: Extratropical transition of tropical cyclones over the western North Pacific. Part I: Evolution of structural characteristics during the transition process. Mon. Wea. Rev., 128, 2613-2633, https://doi.org/10.1175/ 1520-0493(2000)128<2613:ETOTCO >2.0.CO;2.

_, and J. M. Dea, 2009: Downstream development associated with the extratropical transition of tropical cyclones over the western North Pacific. Mon. Wea. Rev., 137, 1295-1319, https://doi.org/10.1175/2008MWR2558.1.

Hart, R. E., 2003: A cyclone phase space derived from thermal wind and thermal asymmetry. Mon. Wea. Rev., 131, 585-616, https://doi.org/10.1175/1520-0493(2003)131<0585:ACPSDF> 2.0.CO;2.

—, and J. L. Evans, 2001: A climatology of the extratropical transition of Atlantic tropical cyclones. J. Climate, 14, 546-564, https:// doi.org/10.1175/1520-0442(2001)014<0546:ACOTET>2.0.CO;2.

,-- , and C. Evans, 2006: Synoptic composites of the extratropical transition life cycle of North Atlantic tropical cyclones: Factors determining posttransition evolution. Mon. Wea. Rev., 134, 553-578, https://doi.org/10.1175/MWR3082.1.

Ito, R., T. Takemi, and O. Arakawa, 2016: A possible reduction in the severity of typhoon wind in the northern part of Japan under global warming: A case study. SOLA, 12, 100-105, https://doi.org/10.2151/SOLA.2016-023.

Jones, S. C., and Coauthors, 2003: The extratropical transition of tropical cyclones: Forecast challenges, current understanding, and future directions. Wea. Forecasting, 18, 10521092, https://doi.org/10.1175/1520-0434(2003)018<1052: TETOTC $>2.0 . C O ; 2$.

Jung, C., and G. M. Lackmann, 2019: Extratropical transition of Hurricane Irene (2011) in a changing climate. J. Climate, 32, 4847-4871, https://doi.org/10.1175/JCLI-D-18-0558.1.

Keller, J. H., and Coauthors, 2019: The extratropical transition of tropical cyclones. Part II: Interaction with the midlatitude flow, downstream impacts, and implications for predictability. Mon. Wea. Rev., 147, 1077-1106, https://doi.org/10.1175/ MWR-D-17-0329.1.

Kimura, F., and A. Kitoh, 2007: Downscaling by pseudo global warming method. Final Report of ICCAP (Impact of Climate
Changes on Agricultural Production System in Arid Areas), 43-46, http://www.chikyu.ac.jp/iccap/ICCAP_Final_Report/2/ 4-climate_kimura.pdf.

Kitabatake, N., 2011: Climatology of extratropical transition of tropical cyclones in the western North Pacific defined by using cyclone phase space. J. Meteor. Soc. Japan, 89, 309-325, https://doi.org/10.2151/jmsj.2011-402.

Klein, P. M., P. A. Harr, and R. L. Elsberry, 2000: Extratropical transition of western North Pacific tropical cyclones: An overview and conceptual model of the transformation stage. Wea. Forecasting, 15, 373-395, https://doi.org/10.1175/15200434(2000)015<0373:ETOWNP>2.0.CO;2.

Knapp, K. R., M. C. Kruk, D. H. Levinson, H. J. Diamond, and C. J. Neumann, 2010: The International Best Track Archive for Climate Stewardship (IBTrACS): Unifying tropical cyclone data. Bull. Amer. Meteor. Soc., 91, 363-376, https://doi.org/ 10.1175/2009BAMS2755.1.

Knutson, T. R., and Coauthors, 2010: Tropical cyclones and climate change. Nat. Geosci., 3, 157-163, https://doi.org/10.1038/ ngeo779.

Kofron, D. E., E. A. Ritchie, and J. S. Tyo, 2010a: Determination of a consistent time for the extratropical transition of tropical cyclones. Part I: Examination of existing methods for finding "ET time." Mon. Wea. Rev., 138, 4328-4343, https://doi.org/ 10.1175/2010MWR3180.1.

,-- , and ——, 2010b: Determination of a consistent time for the extratropical transition of tropical cyclones. Part II: Potential vorticity metrics. Mon. Wea. Rev., 138, 43444361, https://doi.org/10.1175/2010MWR3181.1.

Korty, R. L., K. A. Emanuel, M. Huber, and R. A. Zamora, 2017: Tropical cyclones downscaled from simulations with very high carbon dioxide levels. J. Climate, 30, 649-667, https://doi.org/ 10.1175/JCLI-D-16-0256.1.

Kossin, J. P., K. A. Emanuel, and S. J. Camargo, 2016: Past and projected changes in western North Pacific tropical cyclone exposure. J. Climate, 29, 5725-5739, https://doi.org/10.1175/ JCLI-D-16-0076.1.

Lackmann, G. M., 2013: The south-central U.S. flood of May 2010: Present and future. J. Climate, 26, 4688-4709, https://doi.org/ 10.1175/JCLI-D-12-00392.1.

__, 2015: Hurricane Sandy before 1900 and after 2100. Bull. Amer. Meteor. Soc., 96, 547-560, https://doi.org/10.1175/ BAMS-D-14-00123.1.

Liu, M., G. A. Vecchi, J. A. Smith, and H. Murakami, 2017: The present-day simulation and twenty-first-century projection of the climatology of extratropical transition in the North Atlantic. J. Climate, 30, 2739-2756, https://doi.org/10.1175/ JCLI-D-16-0352.1.

Mallard, M. S., G. M. Lackmann, A. Aiyyer, and K. Hill, 2013a: Atlantic hurricanes and climate change. Part I: Experimental design and isolation of thermodynamic effects. J. Climate, 26, 4876-4893, https://doi.org/10.1175/JCLI-D-12-00182.1.

,$- \ldots$, and,$- 2013 \mathrm{~b}$ : Atlantic hurricanes and climate change Part II: Role of thermodynamic changes in decreased hurricane frequency. J. Climate, 26, 8513-8528, https://doi.org/ 10.1175/JCLI-D-12-00183.1.

Malmquist, D. L., 1999: Meteorologists and insurers explore extratropical transition of tropical cyclones. Eos, Trans. Amer. Geophys. Union, 80, 79-80, https://doi.org/10.1029/99EO00055.

Meinshausen, M., and Coauthors, 2011: The RCP greenhouse gas concentrations and their extensions from 1765 to 2300 . Climatic Change, 109, 213-241, https://doi.org/10.1007/ s10584-011-0156-z. 
Merrill, R. T., 1988: Environmental influences on hurricane intensification. J. Atmos. Sci., 45, 1678-1687, https://doi.org/ 10.1175/1520-0469(1988)045<1678:EIOHI>2.0.CO;2.

Michaelis, A. C., 2019: Climate change effects on the extratropical transition of tropical cyclones in high-resolution global simulations. North Carolina State University, Ph.D. thesis, 156 pp., https://repository.lib.ncsu.edu/handle/1840.20/36292.

_- G. M. Lackmann, and W. A. Robinson, 2019: Evaluation of a unique approach to high-resolution climate modeling using the Model for Prediction Across Scales-Atmosphere (MPAS-A) version 5.1. Geosci. Model Dev., 12, 3725-3743, https://doi.org/ 10.5194/gmd-12-3725-2019.

Mizuta, R., O. Arakawa, T. Ose, S. Kusunoki, H. Endo, and A. Kitoh, 2014: Classification of CMIP5 future climate responses by the tropical sea surface temperature changes. SOLA, 10, 167-171, https://doi.org/10.2151/SOLA.2014-035.

Rasmussen, R., and Coauthors, 2011: High-resolution coupled climate runoff simulations of seasonal snowfall over Colorado: A process study of current and warmer climate. J. Climate, $\mathbf{2 4}$, 3015-3048, https://doi.org/10.1175/2010JCLI3985.1.

Schär, C., C. Frei, D. Lüthi, and H. C. Davies, 1996: Surrogate climate-change scenarios for regional climate models. Geophys. Res. Lett., 23, 669-672, https://doi.org/10.1029/96GL00265.

Semmler, T., S. Varghese, R. McGrath, P. Nolan, S. Wang, P. Lynch, and C. O'Dowd, 2008: Regional model simulation of North Atlantic cyclones: Present climate and idealized response to increased sea surface temperature. J. Geophys. Res., 113, D02107, https://doi.org/10.1029/2006JD008213.

Shen, Y., Y. Sun, Z. Zhong, K. Liu, and J. Shi, 2018: Sensitivity experiments on the poleward shift of tropical cyclones over the western North Pacific under warming ocean conditions. J. Meteor. Res., 32, 560-570, https://doi.org/10.1007/ s13351-018-8047-0.

Skamarock, W. C., J. B. Klemp, M. G. Duda, L. D. Fowler, S. Park, and T. D. Ringler, 2012: A multiscale nonhydrostatic atmospheric model using centroidal Voronoi tesselations and C-grid staggering. Mon. Wea. Rev., 140, 3090-3105, https://doi.org/10.1175/MWR-D-11-00215.1.

Studholme, J., K. I. Hodges, and C. M. Brierley, 2015: Objective determination of the extratropical transition of tropical cyclones in the Northern Hemisphere. Tellus, 67, 24474, https://doi.org/10.3402/tellusa.v67.24474.

Torres-Vazquez, A. P., 2018: Evaluating the effects of a warming climate on the spatiotemporal characteristics of tropical cyclones. Master's thesis, Department of Marine, Earth and Atmospheric Sciences, North Carolina State University, 134 pp.

Trapp, R. J., and K. A. Hoogewind, 2016: The realization of extreme tornadic storm events under future anthropogenic climate change. J. Climate, 29, 5251-5265, https://doi.org/ 10.1175/JCLI-D-15-0623.1.

Ullrich, P. A., and C. M. Zarzycki, 2017: TempestExtremes: A framework for scale-insensitive pointwise feature tracking on unstructured grids. Geosci. Model Dev., 10, 1069-1090, https:// doi.org/10.5194/gmd-10-1069-2017.

Vecchi, G. A., and B. J. Soden, 2007: Increased tropical Atlantic wind shear in model projections of global warming. Geophys. Res. Lett., 34, L08702, https://doi.org/10.1029/ 2006 GL028905.

Walsh, K. J. E., and J. J. Katzfey, 2000: The impact of climate change on the poleward movement of tropical cyclone-like vortices in a regional climate model. J. Climate, 13, 11161132, https://doi.org/10.1175/1520-0442(2000)013<1116: TIOCCO $>2.0 . \mathrm{CO} ; 2$

, and Coauthors, 2015: Hurricanes and climate: The U.S. CLIVAR Working Group on hurricanes. Bull. Amer. Meteor. Soc., 96, 997-1017, https://doi.org/10.1175/BAMS-D-1300242.1 .

Willison, J., W. A. Robinson, and G. M. Lackmann, 2013: The importance of resolving mesoscale latent heating in the North Atlantic storm track. J. Atmos. Sci., 70, 2234-2250, https:// doi.org/10.1175/JAS-D-12-0226.1.

Wood, K. M., and E. A. Ritchie, 2014: A 40-year climatology of extratropical transition in the eastern North Pacific. J. Climate, 27, 5999-6015, https://doi.org/10.1175/JCLI-D-13-00645.1.

Zarzycki, C. M., and P. A. Ullrich, 2017: Assessing sensitivities in algorithmic detection of tropical cyclones in climate data. Geophys. Res. Lett., 44, 1141-1149, https://doi.org/10.1002/ 2016GL071606.

_ D. R. Thatcher, and C. Jablonowski, 2017: Objective tropical cyclone extratropical transition detection in high-resolution reanalysis and climate model data. J. Adv. Model. Earth Syst., 9, 130-148, https://doi.org/10.1002/2016MS000775.

Zhang, L., K. B. Karnauskas, J. P. Donnelly, and K. Emanuel, 2017: Response of the North Pacific tropical cyclone climatology to global warming: Application of dynamical downscaling to CMIP5 models. J. Climate, 30, 1233-1243, https://doi.org/ 10.1175/JCLI-D-16-0496.1. 